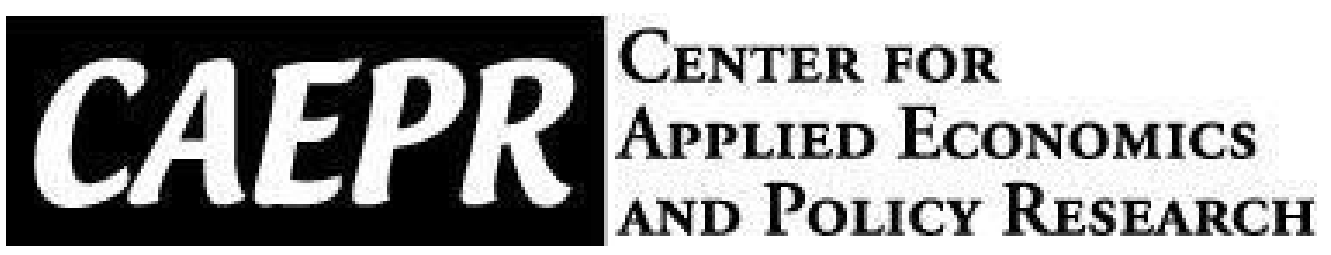

CAEPR Working

Paper

\#2017-004

\title{
National Differentiation and Industry-Wide Scale Effects
}

\author{
Ahmad Lashkaripour \\ Indiana University \\ Volodymyr Lugovskyy \\ Indiana University
}

April 18, 2017

This paper can be downloaded without charge from the Social Science Research Network electronic library at https://ssrn.com/abstract=2954731

The Center for Applied Economics and Policy Research resides in the Department of Economics at Indiana University Bloomington. CAEPR can be found on the Internet at: http://www.indiana.edu/ caepr. CAEPR can be reached via email at caepr@indiana.edu or via phone at 812-855-4050.

@2017 by Ahmad Lashkaripour and Volodymyr Lugouskyy. All rights reserved. Short sections of text, not to exceed two paragraphs, may be quoted without explicit permission provided that full credit, including $₫$ notice, is given to the source. 


\title{
National Differentiation and Industry-Wide Scale Effects*
}

\author{
Ahmad Lashkaripour \\ Indiana University
}

\author{
Volodymyr Lugovskyy \\ Indiana University
}

First version: August, 2016

This version: April 18, 2017

\begin{abstract}
In a large class of trade models, trading patterns and the corresponding welfare gains depend on the scale elasticity - a deep parameter that governs industry-wide returns to scale. Noting that the scale elasticity depends on the extent to which technologies or products are nationally differentiated, we develop an empirical strategy to structurally estimate the scale elasticity across various industries. A trade model that features our estimated scale elasticity captures the negative relationship between population size and real income, which eludes standard trade models. Furthermore, we find that scale elasticities display considerable inter-industry variation. Accounting for these previously overlooked variations greatly modifies the estimated gains from trade.
\end{abstract}

\section{Introduction}

Aggregate returns to scale are the cornerstone of modern trade theory. They govern both trading patterns and the gains from trade, all through a structural parameter commonly known as the scale elasticity. Despite being a foundational parameter, the empirical literature offers little in terms of estimating the

${ }^{*}$ We are grateful to Adina Ardelean, Alan Deardorff, Farid Farrokhi, Ana Cecilia Fieler, David Hummels, Andrés Rodríguez-Clare, Peter Schott, Anson Soderbery, and seminar participants at Indiana University, the Midwest Trade and UECE Lisbon Meetings for helpful comments and suggestions. Lugovskyy thanks Indiana University SSRC for financial support. All remaining errors are our own. 
scale elasticity. Instead, quantitative trade models generally normalize the scale elasticity - a practice that either distorts the predicted gains from trade (Kucheryavyy et al. (2015)) or implies counterfactual relations between population size and aggregate economic outcomes (Ramondo et al. (2016); Rose (2006)).

Against the backdrop of these issues, we show that in a wide class of trade models the scale elasticity depends on the extent to which technologies or products are nationally differentiated. Building on this observation, we develop a novel method for structurally estimating the scale elasticity for a wide range of industries. Our estimates identify the relative importance of scale economies across industries and provide an empirical foundation for gains-from-trade estimation in multi-industry trade models. Our findings also help explain the negative relationship between population size and real income, which has long eluded standard trade models. ${ }^{1}$

We build on the finding of Kucheryavyy et al. (2015) that the scale elasticity could reflect the degree of national product differentiation in models with internal economies of scale (e.g., Krugman (1980); Melitz (2003)) or returns to agglomeration in models with external economies of scale. We extend this idea and show that the scale elasticity is also key in idea-based trade models (e.g., Eaton and Kortum $(2001,2002)$ ) where it reflects the degree of national technology differentiation. Irrespective of the underlying principles, however, the scale elasticity, like the trade elasticity, enters the import demand function and the gains from trade formula in a universal fashion. Based on this result, we derive a structural import demand function that underlies a large class of trade models.

To empirically identify the scale elasticity, we estimate the structural import demand function with data on the universe of Colombian import transactions. Our data set includes all import transactions into Colombia pertaining to a 10-digit (Harmonized System) product category in the 2007-2013 period. Importantly, the dataset identifies all firms exporting to Colombia, allowing us to distinguish imported varieties up to a country-firm-product combination in a given year. Our estimation strategy borrows heavily from developments in the fields of labor economics and industrial organization. In particular, our estima-

\footnotetext{
${ }^{1}$ Introducing domestic trade frictions into standard trade models usually moderates the overstated relation between population size and real income. However, even after controlling for direct measures of internal trade frictions, the implied relationship remains counterfactually strong (Ramondo et al. (2016)). The other two channels that could also mitigate the overstated scale-income relationship are multinational production and technology diffusion (Ramondo and Rodríguez-Clare (2010)).
} 
tion resembles the demand estimations of Berry (1994) and Berry et al. (1995). Likewise, to handle endogeneity, we develop an approach inspired by Bartik (1991).

Utilizing monthly and annual variations in the data, we estimate (i) an economy-wide (uniform) scale elasticity and (ii) sector-wide scale elasticities. The economy-wide scale elasticity is estimated at $\alpha=0.6$ across all manufacturing sectors, whereas the sector-wide elasticities display considerable intersectoral variation. Overall, our estimates point to elasticities that are greater than those assumed in perfectly competitive trade models $(\alpha=0)$, but smaller than those in monopolistically competitive models $(\alpha=1)$. Putting our estimates in perspective, a scale elasticity of 0.6 implies that a $10 \%$ increase in the scale of a national industry increases industry-wide sales by only $6 \% .^{2}$ This less-than-proportional increase reflects the fact that products and technologies are less differentiated intra-nationally than inter-nationally-namely, national product or knowledge differentiation.

To study the macro-level implications, we calibrate a multi-country gravity model that incorporates our estimated economy-wide scale elasticity. The calibrated model correctly predicts the international relation between population size and real per capita income, which is weakly negative. In comparison, a standard Krugman-Melitz model, which features a counterfactually large scale elasticity, predicts a strong, positive relationship between per capita income and population size. ${ }^{3}$ Introducing domestic trade frictions only partially mitigates this counterfactual prediction (Ramondo et al. (2016)).

Our sector-wide scale elasticity estimates provide an empirical foundation for estimating the gains from trade in multi-sector trade models. Kucheryavyy et al. (2015) and Costinot and Rodríguez-Clare (2014) point out that the gains from trade depend on both the trade elasticity and the scale elasticity. The trade elasticity governs the overall size of the gains from trade, and has been estimated extensively at various levels of disaggregation (Broda and Weinstein (2006); Simonovska and Waugh (2014); Caliendo and Parro (2014)). The scale elasticity (which we, to our knowledge, are the first to estimate) governs the international allocation of the gains from trade.

\footnotetext{
${ }^{2}$ The scale of an industry is reflected either in the size of the industry-wide labor force or the number of incumbent firms, both of which are strongly correlated in theory.

${ }^{3}$ The Eaton and Kortum (2002) model would also predict a counterfactually strong incomesize elasticity given that the stock of non-rival ideas in any country is proportional to its population size (see Ramondo et al. (2016)).
} 
Accounting for sectoral variations in the scale elasticity, we estimate gains from trade that are considerably different from those computed under normalized elasticities. In particular, sectors such as machinery or chemicals feature stronger scale effects and offer higher returns to specialization. Accounting for these variations, Korea and Taiwan (which have a comparative advantage in high-return sectors) gain relatively more from trade at the expense of countries such as Greece and Russia. Additionally, we find that the gains from trade are less pro-small than those predicted by the standard Krugman-Melitz specification. ${ }^{4}$

Our analysis provides an empirical basis for discriminating between two classic but competing views of intra-industry trade. The first one is the socalled biological view, where nationally-differentiated products or technologies arise in response to peculiarities in local demand (Bhagwati (1982); Feenstra (1982)). The second one is the popular view that intra-industry trade is driven by increasing returns to scale (Krugman (1980)). Overall, we estimate a greater role for economies of scale in most sectors. Nonetheless, with the exception of a few sectors, national differentiation is an economically significant force.

The fact that products or technologies are less differentiated intra-nationally rejects the independence of irrelevant alternatives (IIA) - an assumption imposed by many contemporary trade theories. ${ }^{5}$ While the IIA assumption has garnered considerable attention in the industrial organization literature, the trade literature has only recently tested this assumption against data. Redding and Weinstein (2016) estimate an international demand system that relaxes the IIA assumption by accommodating heterogeneous taste across consumers. Adao et al. (2015) estimate a trade model that (unlike standard CES models) permits varieties from certain countries to be closer substitutes. Our paper contributes to this emerging literature by highlighting another aspect of the trade data that is at odds with the IIA assumption.

At a broader level, this paper contributes to our understanding of aggregate scale effects, which are central to other domains of economics such as growth theory. Idea-based growth models exhibit scale effects that are at odds with

\footnotetext{
${ }^{4}$ This simply reflects the fact that the marginal value of access to new varieties increases less-than-proportionally with the size of a trading partner.

${ }^{5}$ The IIA condition is defined by Arrow (1950) in his impossibility theorem as "The social preferences between alternatives $x$ and $y$ depend only on the individual preferences between $x$ and $y . "$ This requires the choice over any two alternatives not be influenced by the inclusion of a third alternative. In the CES and logit models, IIA implies the symmetry of all cross-price elasticities and the over-evaluation of variety (e.g., Hausman (1996)).
} 
20th century empirical evidence (Jones (1999)). Our micro-level estimates may shed new light on this apparent discrepancy. Our paper also contributes to a vibrant literature that analyzes optimal country size (Alesina et al. (2000); Alesina and Spolaore (2005)). While this literature often assumes a congestion cost associated with national size, the origins of such costs are less understood. Our estimates indicate that these costs partially reflect national differentiation. However, one should exercise caution when interpreting our results in the aforementioned context. Our estimates identify one of the many advantages (or disadvantages) of political disintegration. However, to assess the overall effects of political disintegration one should account for other relevant factors and the corresponding trade-offs.

\section{Empirical Regularities}

Our theory, which is formally presented in Section (3), describes how the scale elasticity regulates scale-driven relations in mainstream trade models. Before outlining the theory we present our data set and suggestive evidence about the magnitude of these scale-driven relations (e.g., the relationship between population size, real income and export sales). The macro-level evidence presented in this section is merely suggestive, whereas later in Section (4) we formally estimate the scale elasticity using micro-level data.

\subsection{Data}

Our primary data source covers daily import transactions from the Colombian Customs Office for the 2007-2013 period. ${ }^{6}$ The data include detailed information about each transaction, such as the Harmonized System 10-digit product category (HS10), importing and exporting firms, f.o.b. (free on board) and c.i.f. (customs, insurance, and freight) values of shipments in US dollars, quantity, unit of measurement (of quantity), freight in US dollars, insurance in US dollars, value-added tax in US dollars, country of origin, and weight. The uniqueness of this data set is that it reports the identities of all foreign firms exporting to Colombia. This allows us to define variety as a firm-product combination, whereas papers focusing on the international exports to a given location typi-

\footnotetext{
${ }^{6}$ The data is obtained from Datamyne, a company that specializes in documenting import and export transactions in the Americas. For more detail please see www.datamyne.com.
} 
Table 1: Summary Statistics of the Colombian Import Data.

\begin{tabular}{|c|c|c|c|c|c|c|c|}
\hline \multirow[b]{2}{*}{ Statistic } & \multicolumn{7}{|c|}{ Year } \\
\hline & 2007 & 2008 & 2009 & 2010 & 2011 & 2012 & 2013 \\
\hline F.O.B. value (billion dollars) & 30.77 & 37.26 & 31.39 & 38.41 & 52.00 & 55.79 & 56.92 \\
\hline$\frac{\text { C.I.F. value }}{\text { F.O.B. value }}$ & 1.08 & 1.07 & 1.05 & 1.06 & 1.05 & 1.05 & 1.05 \\
\hline$\frac{\text { C.I.F. }+ \text { tax value }}{\text { F.O.B. value }}$ & 1.28 & 1.21 & 1.14 & 1.19 & 1.15 & 1.18 & 1.15 \\
\hline No. of exporting countries & 210 & 219 & 213 & 216 & 213 & 221 & 224 \\
\hline No. of imported varieties & 483,286 & 480,363 & 457,000 & 509,524 & 594,918 & 633,008 & 649,561 \\
\hline
\end{tabular}

Notes: Tax value includes import tariff and value-added tax (VAT). The number of varieties corresponds to the number of country-firm-product combination imported by Colombia in a given year.

cally treat varieties as a more aggregate country-product combination. Table 1 reports a summary of basic trade statistics in our data.

We also use aggregate statistics from other sources: (i) aggregate bilateral merchandise trade flows from the U.N. COMTRADE database (Comtrade (2010)); (ii) national account data from the World Bank database (World-Bank (2012)); (iii) monthly average exchange rates from the Bank of Canada; ${ }^{7}$ and (iv) data on bilateral distance, common official language, and borders from Mayer and Zignago (2011). Below, we present three empirical patterns regarding the relationship between population size, the number of exported varieties, export values, and real per capita income.

\subsection{Suggestive Evidence}

In the following, we present three stylized facts, which suggest that (i) export sales increase less rapidly with national scale than what the standard love-ofvariety specification assumes, and as result, (ii) the relationship between real per capita income and national scale (i.e. population size) is weaker than what the standard trade models predict.

Pattern 1.A. The nominal number of exported varieties increases proportionally with population size...

We establish this pattern using the transaction-level import data from Colombia. We define a variety as a country-firm-product combination imported by

\footnotetext{
${ }^{7}$ See $h t t p: / / w w w . b a n k o f c a n a d a . c a / r a t e s / e x c h a n g e / m o n t h l y$-average-lookup/.
} 
Table 2: The Number of Exported Varieties $\times$ National Characteristics

Dependent variable: Number of exported varieties (log)

\begin{tabular}{|c|c|c|c|c|c|c|}
\hline \multirow[b]{2}{*}{ Sample } & \multicolumn{4}{|c|}{ Regressor (log) } & \multirow[b]{2}{*}{$R^{2}$} & \multirow[b]{2}{*}{ Obs. } \\
\hline & Population & GDP per capita & Distance & Border & & \\
\hline All Products & $\begin{array}{c}1.01^{* * *} \\
(0.03)\end{array}$ & $\begin{array}{c}1.09^{* * *} \\
(0.03)\end{array}$ & $\begin{array}{c}-0.42^{* * *} \\
(0.06)\end{array}$ & $\begin{array}{c}1.42^{* * *} \\
(0.27)\end{array}$ & 0.71 & 839 \\
\hline Manufacturing & $\begin{array}{c}1.02^{* * *} \\
(0.03)\end{array}$ & $\begin{array}{c}1.08^{* * *} \\
(0.04)\end{array}$ & $\begin{array}{c}-0.34^{* * *} \\
(0.07)\end{array}$ & $\begin{array}{c}1.50^{* * *} \\
(0.29)\end{array}$ & 0.69 & 832 \\
\hline
\end{tabular}

Notes: Estimation results of Equation (1). Robust standard errors in parentheses. ${ }^{*}$ significant at $10 \% ;{ }^{* *}$ significant at $5 \%$; ${ }^{* * *}$ significant at $1 \%$. The estimation is conducted with year fixed effects.

Colombia in a given year. Using this definition, we calculate the nominal number of varieties exported to Colombia from country $i$ in year $t$, labeling it $N_{i t}$. We then run the following regression:

$\ln N_{i t}=\beta_{t}+\beta_{P} \ln$ Population $_{i t}+\beta_{Y}$ GDP per capita ${ }_{i t}+\beta_{D}$ Dist $_{i}+\beta_{B}$ Border $_{i}+\varepsilon_{i t}$,

where $\beta_{t}$ denotes a set of year dummy variables. The results (displayed in Table 2) suggest that the number of exported varieties increases proportionally with population size, which supports the prediction of a standard variety-based trade model (e.g., Krugman (1980) and Melitz (2003)). Similarly, this fact aligns with the proposition in Eaton and Kortum (2001) that the stock of technological knowledge in a country is proportional to its population size. Existing theories, however, usually impose an additional assumption: export sales increase proportionally with the number of exported varieties or the stock of technological knowledge. That is to say, consumers do not discriminate between product varieties based on country of origin. Or, regarding technologies, the assumption simply states that firm-specific technologies are as similar within countries as across countries. Either way, the following pattern challenges this widespread assumption.

Pattern 1.B. ...But export sales increase less-than-proportionally with the nominal number of exported varieties.

\footnotetext{
${ }^{8}$ For example, in 2007, a product with an HS10 code 8428101000 (Ascensores sin cabina ni contrapeso -Elevators without a cabin or counterweight), was exported to Colombia by firm "MITSUBISHICO" from two countries of origin-namely, Japan and Thailand. We treat these as two distinct varieties: one exported to Colombia by Japan and one exported by Thailand.
} 
To establish the above pattern, we estimate the elasticity of $X_{i t}$ ( country $i^{\prime} s$ export sales to Colombia in year $t$ ) with respect to $N_{i t}$ (the nominal number of varieties exported by country $i$ to Colombia in year $t$ ):

$$
\ln X_{i t}=\phi_{t}+\phi_{N} \ln N_{i t}+\varepsilon_{i t}
$$

The above equation resembles a constant elasticity gravity estimation. Silva and Tenreyro (2006) point out that in the presence of heteroskedasticity, consistent estimates of the elasticity $\phi_{N}$ could be attained with a Poisson pseudomaximum-likelihood (PPML) estimator. Complying with this well-established argument, we estimate Equation 2 with a PPML estimator (OLS estimates are also reported for comparison). The estimation results are displayed in Table 3 , and they suggest that export sales increase less-than-proportionally with the number of exported varieties: $\Phi_{N}<1$. In other words, while the nominal number of exported varieties $\left(N_{i t}\right)$ increases proportionally with population size, the effective number of varieties $\left(N_{i t}^{\phi_{N}}\right)$ increases less-than-proportionally.

Pattern 1.B contrasts the proportionality assumption (i.e., $\Phi_{N} \equiv 1$ ) that underlies the standard love-of-variety specification in Krugman (1980). Similarly, it contrasts the common assertion that the stock of frontier technologies in a country increases proportionally with the number of firms (Eaton and Kortum (2001); Ramondo et al. (2016)). Instead, Pattern 1.B suggests that because product varieties or technologies are more similar within the same country, export sales increase less-than-proportionally with each added variety: $\Phi_{N}<1$. Put in a broader context, the proportionality assumptions underlying standard trade models are analogous to the independence of irrelevant alternatives (IIA) assumption. Pattern 1.B, therefore, suggests that the IIA assumption may be too restrictive.

Importantly, one should exercise caution when interpreting the above results. We are analyzing the number of exported firm-product combinations, as opposed to the number of exporting firms (as in Fernandes et al. (2015)) or the number of exported product categories (as in Hummels and Klenow (2005)). This distinction is critical because $(i)$ each firm typically exports multiple product lines, or (ii) each product category features multiple exporting firms. In fact, while sales per variety fall with total exports, sales per firm increase, which reflects the fact that firms, in general, export multiple product lines. ${ }^{9}$ Similarly, in line with the findings of Hummels and Klenow (2005), sales per product cate-

\footnotetext{
${ }^{9}$ We estimate that the number of exporting firms increases with less-than-proportionally
} 
Table 3: Export Sales $\times$ Number of Exported Varieties.

Dependent: Total Export Sales to Colombia (log)

\begin{tabular}{lcccccc}
\hline \multirow{2}{*}{ Estimator } & \multicolumn{2}{c}{ All product } & & \multicolumn{2}{c}{ Manufacturing } \\
\cline { 2 - 3 } \cline { 6 - 7 } No. of Exported Varieties (log) & $0.82^{* * *}$ & $0.68^{* * * *}$ & & $0.82^{* * *}$ & $0.70^{* * *}$ \\
& $(0.03)$ & $(0.03)$ & & $(0.02)$ & $(0.02)$ \\
$R^{2}$ & 0.87 & 0.79 & & 0.87 & 0.78 \\
Observations & 861 & 861 & & 854 & 854 \\
\hline
\end{tabular}

Notes: Estimation results of Equation (2). Robust standard errors in parentheses. ${ }^{* * *}$ denotes significance at $1 \%$. The estimation is conducted with year fixed effects on a panel of 123 exporting countries over 7 years.

gory also increase with total sales. Again, this observation reflects the fact that each additional product category typically features multiple firms. Altogether, we believe Patterns 1.A and 1.B lend themselves well to inferences regarding the import demand system. In particular, the co-existence of multiple varieties confirms the love-of-variety. However, the love-of-variety and the resulting scale economies may be more nuanced than is generally assumed.

The previous two patterns shed new light on aggregate scale effects by outlining the empirical relationship between national scale and export sales. The following pattern investigates scale effects from a different angle; it highlights the relationship between real per capita income and population size, which has transformed over time.

Pattern 2. With the rise of international trade, the relationship between real income per capita and population size has transformed from weakly positive in the 1960s to negative in the late 2000s.

Figure 1 illustrates the above pattern. The bottom panel plots the relationship between the (expenditure side) real income per capita and population size for the years 1960 and 2008. The relationship is weakly positive in 1960 but negative in 2008. The decline in the size-income relationship coincides with the rise of international trade (Figure 1, top panel). To an extent, this trend helps us understand why previous studies tend to find no systematic relationship between population size and national prosperity (e.g., Rose (2006)): both the magnitude with population size, whereas total sales increase more-than-proportionally to the number of exporting firms. This result resonates with the findings in Fernandes et al. (2015) plus Eaton et al. (2011). 
Figure 1: The rise of international trade and the diminishing relationship between real income per capita and population size.

_ Relation between Real Income Per Capita and Population

- - Trade as a share of World GDP

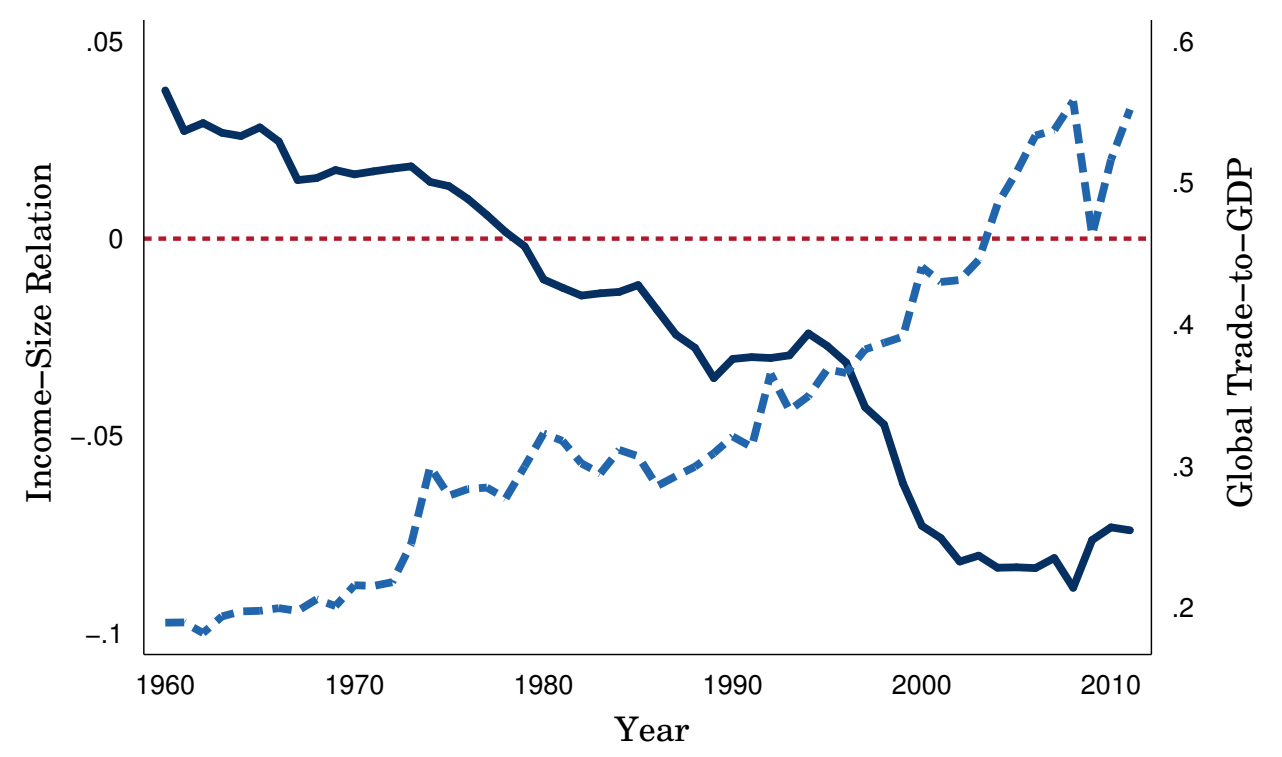

- $2008 \Delta 1960$

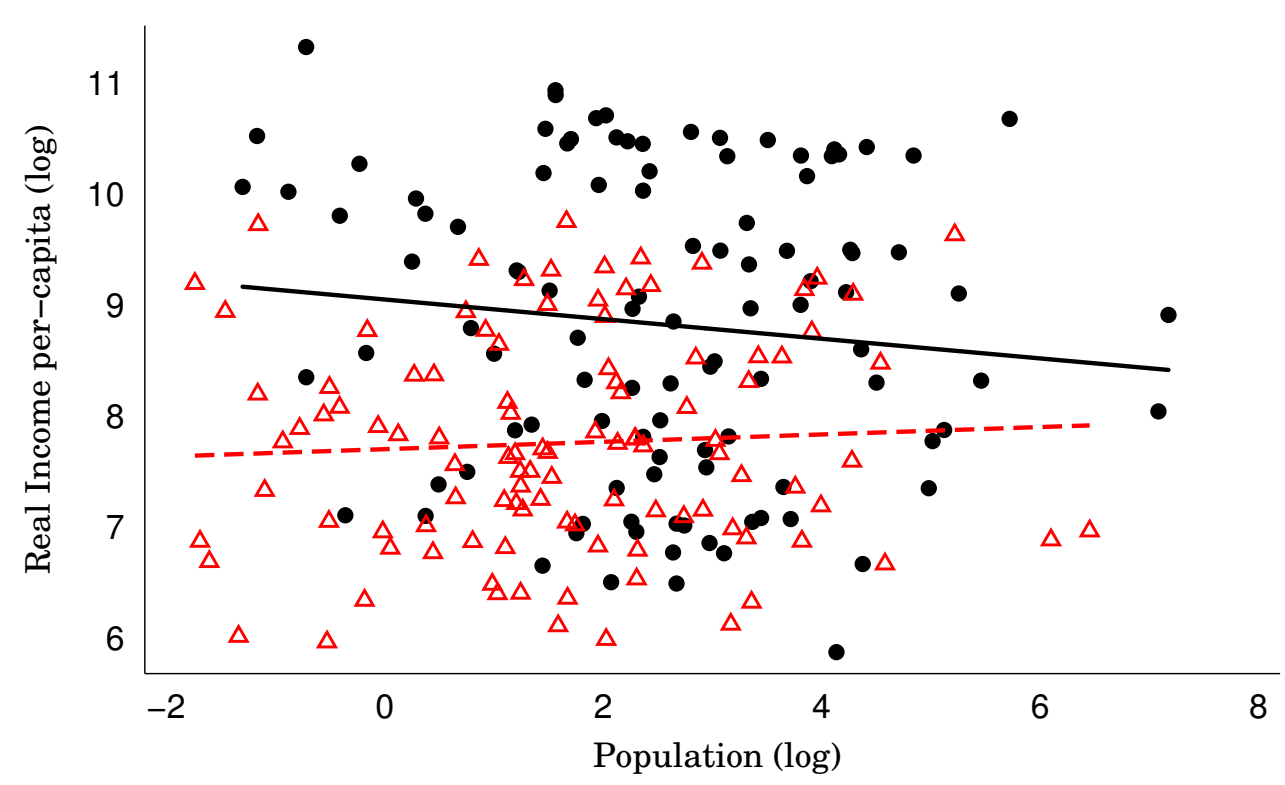

Notes: The top panel suggests that after 1980, larger countries (on average) have a lower real income per-capita. The bottom panel plots the size-income relationship for the years 1960 and 2006. 
and the direction of the relationship depend on the size of the trade barriers and can change over time. The negative relationship between income and size, however, cannot be easily reconciled with standard gravity trade models. Typically, trade models predict that international trade should weaken the effect of population size on the standard of living. However, a standard trade model fitted to trade data in 2008 will nevertheless predict a positive relationship between population size and real per capita income (see Section 5). In other words, the national scale-effects in standard trade models are too strong to be eliminated by the observed levels of economic integration.

\section{Theory}

The previous section reported basic correlations between national scale and economic outcomes (e.g., international sales and per capita income). In an important class of trade models, these scale-driven relations are regulated by a deep parameter called the scale elasticity. In this section, we demonstrate that within this class of models, irrespective of the underlying micro-foundation, the scale elasticity appears in the import demand function and the gains from trade formula in a universal fashion. This amounts to establishing that the isomorphism between $(i)$ variety-based models built on product differentiation (e.g., Anderson (1979); Krugman (1980); Chaney (2008)) and (ii) idea-based models built on technology differentiation (e.g., Eaton and Kortum (2001); Eaton and Kortum (2002)) extends beyond what is conventionally believed. In that regard, our theory complements Kucheryavyy et al. (2015) who establish the isomorphism between variety-based models featuring internal economies of scale and models featuring external economies of scale.

The first part of this section has a partial equilibrium flavor. Taking nominal prices as given, we derive a universal import demand function that is common across the class of models we consider, and that can be structurally estimated with standard transaction-level customs data (i.e., data that includes firm-specific sales and unit prices). The second part of this section has a more general equilibrium flavor. We build on the existing literature, to show that if the economy satisfies a set primitive conditions, the isomorphism between the models of interest extends to general equilibrium predictions. In particular, conditional on the trade and scale elasticity parameters, the class of multi-sector models we consider imply the same gains from trade relative to autarky. 
The Environment. The class of models we consider share a common environment, which consists of $N$ countries. There all multiple product categories, each indexed by $h$. The preferences of the representative consumer in country $i$ are characterized by a Cobb-Douglas utility function that aggregates across various product categories

$$
W_{i}=\prod_{h \in H} W_{i, h}^{\beta_{h}},
$$

where $W_{i, h}$ and $\beta_{h}$ respectively denote the sub-utility corresponding to, and the share of income spent on product $h .{ }^{10}$ Depending on the underlying microfoundation, within-product consumption shares are governed by either (i) horizontal product differentiation or (ii) comparative cost advantage resulting from technology differentiation. Below, we separately outline the two classes of models that build on these two distinct views.

\subsection{Variety-based models}

Variety-based trade models, exemplified by Krugman (1980), are structured around horizontal product differentiation. Below, we outline a generalized varietybased trade model that nests the Krugman and Armington models as a special case-the model closely resembles the nested Krugman model in Kucheryavyy et al. (2015). The underlying assumption is that preferences, within product category $h$, are described by a nested CES utility function that aggregates across various firm-specific varieties in that product category. In particular,

$$
\begin{aligned}
W_{i, h}= & \max _{q_{\omega i, h}}\left[\sum_{j=1}^{N}\left(\sum_{\omega \in \Omega_{j i, h}}\left(\frac{q_{\omega i, h}}{\phi_{\omega i, h}}\right)^{\frac{\eta_{h}-1}{\eta_{h}}}\right)^{\frac{\eta_{h}}{\eta_{h}-1} \cdot \frac{\sigma_{h}-1}{\sigma_{h}}}\right]^{\frac{\sigma_{h}}{\sigma_{h}-1}} \\
\text { s.t. } & \sum_{j=1}^{N} \sum_{\omega \in \Omega_{j i, h}} p_{\omega i, h} q_{\omega i, h}=X_{i, h},
\end{aligned}
$$

where $p_{\omega i, h}, q_{\omega i, h}$, and $\phi_{\omega i, h}$ respectively denote the price, quantity, and quality associated with a firm-specific variety $\omega$ sold to market $i$ in product category $h ; \Omega_{j i, h}$ denotes the set of all varieties exported from country $j$ to market $i$ in product category $h$; and finally, $X_{i, h}=\beta_{h} Y_{i}$ denotes total spending on product category $h$, where $Y_{i}$ is total income in country $i$.

\footnotetext{
${ }^{10}$ One could further fragment the product space into various sectors, where each sector $s$ consists of a set of products $H_{s}$. The expenditure share on sector $s$ will be $\beta_{s} \equiv \sum_{h \in H_{s}} \beta_{h}$, where $\sum_{s=1}^{M} \beta_{s}=1$, by construction.
} 
Parameters $\sigma_{h}$ and $\eta_{h}$ correspond to the inter-national and intra-national elasticities of substitution, respectively. Defining $\alpha_{h} \equiv \frac{\eta_{h}-1}{\sigma_{h}-1}$ and $\theta_{h} \equiv \sigma_{h}-1$, utility maximization implies that the share of income spent on variety $\omega$ from country $j$ (i.e., $\omega \in \Omega_{j i, h}$ ) is given by:

$$
\lambda_{\omega i, h}=\lambda_{\omega \mid j i, h} \times \lambda_{j i, h}
$$

where $\lambda_{\omega \mid j i, h}$ denotes the within-national market share of variety $\omega$-i.e., the share of income spent on variety $\omega$ conditional on buying from country $j$ :

$$
\lambda_{\omega \mid j i, h}=\frac{\left[p_{\omega i, h} / \phi_{\omega i, h}\right]^{-\theta_{h} / \alpha_{h}}}{\sum_{\omega^{\prime} \in \Omega_{j i, h}}\left[p_{\omega^{\prime} i, h} / \phi_{\omega^{\prime} i, h}\right]^{-\theta_{h} / \alpha_{h}}}=\left(\frac{p_{\omega i, h} / \phi_{\omega i, h}}{P_{j i, h}}\right)^{-\theta_{h} / \alpha_{h}}
$$

with $P_{j i, h} \equiv\left[\sum_{\omega^{\prime} \in \Omega_{j i, h}}\left(p_{\omega^{\prime} i, h} / \phi_{\omega^{\prime} i, h}\right)^{-\theta_{h} / \alpha_{h}}\right]^{-\alpha_{h} / \theta_{h}}$ denoting the price index of country $j$ 's exports to market $i$ in product category $h$. $\lambda_{j i, h}$ is the share of country $i$ 's spending on varieties originating from country $j$ :

$$
\lambda_{j i, h}=\frac{\left(\sum_{\omega \in \Omega_{j i, h}}\left[p_{\omega i, h} / \phi_{\omega i, h}\right]^{-\theta_{h} / \alpha_{h}}\right)^{\alpha_{h}}}{\sum_{k=1}^{N}\left(\sum_{\omega^{\prime} \in \Omega_{k i, h}}\left[p_{\omega^{\prime} i, h} / \phi_{\omega^{\prime} i, h}\right]^{-\theta_{h} / \alpha_{h}}\right)^{\alpha_{h}}}=\left(\frac{P_{j i, h}}{P_{i, h}}\right)^{-\theta_{h}}
$$

where $P_{i, h} \equiv\left[\sum_{k=1}^{N}\left(P_{k i, h}\right)^{-\theta_{h}}\right]^{-\frac{1}{\theta_{h}}}$ denotes the price index of product $h$ in country $i$, which aggregates over all national price indexes in product category $h$. Altogether, total sales of variety $\omega \in \Omega_{j i, h}$ in market $i$ will be given by:

$$
\begin{aligned}
x_{\omega i, h} & =\lambda_{\omega \mid j i, h} \cdot \lambda_{j i, h} \times X_{i, h} \\
& =\left(\frac{p_{\omega i, h} / \phi_{\omega i, h}}{P_{j i, h}}\right)^{-\frac{\theta_{h}}{\alpha_{h}}}\left(\frac{P_{j i, h}}{P_{i, h}}\right)^{-\theta_{h}} \beta_{h} Y_{i} .
\end{aligned}
$$

Manipulating the above equation we arrive at the following import demand function (see Appendix A for a formal derivation):

$$
x_{\omega i, h}=\Psi_{i, h}\left(\frac{p_{\omega i, h}}{\phi_{\omega, h}}\right)^{-\theta_{h}}\left(\lambda_{\omega \mid j, h}\right)^{1-\alpha_{h}}
$$

where $\Psi_{i, h} \equiv P_{i, h}^{\theta_{h}} \beta_{h} Y_{i}$. Notice that in the above equation $\alpha_{h} \equiv \sigma_{h}-1 / \eta_{h}-1$ reflects the degree of national product differentiation-i.e., the lower the $\alpha$ the greater the spread between the degrees intra- and inter-national product differ- 
entiation. Two extreme cases of the above demand function are widely-used in quantitative trade models. First, the Armington case where the scope for national product differentiation is complete: $\alpha=0$. Second, the Krugman-Melitz case where there is no scope for national product differentiation: $\alpha=1$.

In Section 3.3, we demonstrate that once the above import demand function is incorporated into a general equilibrium environment, $\alpha$ governs the degree of aggregate returns to scale. Due to this property, $\alpha$ is often referred to as the scale elasticity. Parameter $\theta$, meanwhile, is what trade economist often refer to as the trade elasticity. Aside from $\alpha$ and $\theta$, the above import demand function includes unit prices, $p_{\omega i, h}$, and within-national market shares, $\lambda_{\omega \mid j, h}$, both of which are typically available in customs data, plus the term $\Psi_{i, h}$, which can be treated as a market-product fixed effect.

In the following section, we demonstrate that idea-based trade models, despite their distinct underlying micro-foundation, imply a demand function that is parametrically identical to the one specified above.

\subsection{Idea-based models}

Idea-based trade models, exemplified by Eaton and Kortum (2002), are structured around comparative cost advantage within a product category. Eaton and Kortum (2002) establish how the idea-based framework delivers a gravity equation that is isomorphic to the gravity equation implied by a perfectly competitive variety-based Armington model. Below, we show that the exact isomorphism between variety- and idea-based models extends beyond this particular case. To this end, we present a generalized version of the multi-sector EatonKortum model, and demonstrate its equivalence to the multi-sector nested Krugman model, studied above.

The idea-based framework departs from the variety-based framework in assuming that each product category is comprised of a continuum of homogenous goods. Suppliers have differentiated productivities across the goods in the continuum. To be more specific, let $v$ index a homogeneous good pertaining to product category $h$. The sub-utility of the representative consumer in country $i$ with respect to product category $h$ is a log-linear aggregator across the continuum of goods in that category:

$$
U_{i, h}=\int_{0}^{1} \ln \tilde{q}_{i, h}(v) d v
$$


Country $j$ is comprised of various firms indexed by $\omega$, and $\Omega_{j i, h}$ denotes the set of all firms in country $j$ actively selling to market $i$. Firm $\omega$ supplies good $v$ to market $i$ at the following quality-adjusted (or effective) price:

$$
\tilde{p}_{\omega i, h}(v)=\frac{p_{\omega i, h}}{\varphi_{\omega}(v)}
$$

Whereas $p_{\omega i, h}$, the nominal price from firm $\omega$, is common across all goods in product category $h$, the quality, $\varphi_{\omega}(v)$, varies systematically. For any given good $v$ supplier-specific qualities are drawn independently from the following nested Fréchet joint distribution:

$$
F_{h}(\boldsymbol{\varphi})=\exp \left[-\sum_{k=1}^{N}\left(\sum_{\omega \in \Omega_{k i, h}} T_{\omega, h} \varphi_{\omega}^{-\vartheta_{h}}\right)^{\frac{\theta_{h}}{\vartheta_{h}}}\right],
$$

The above distribution generalizes the basic Fréchet distribution proposed by Eaton and Kortum (2002). In particular, it relaxes the restriction that productivities are perfectly correlated across providers within the same country. Instead, the above distribution allows for productivity differentiation within countries, and for the degrees of within and across-national productivity differentiation ( $\vartheta_{h}$ and $\theta_{h}$ respectively) to diverge- a special case of the distribution where $\vartheta_{h} \longrightarrow \infty$ corresponds to the Eaton and Kortum (2002) specification.

Furthermore, the above distribution has deep theoretical roots. The Fisher-Tippett-Gnedenko theorem states that if ideas are drawn from a (normalized) distribution, in the limit the distribution of the best draw takes the form of a general extreme value (GEV) distribution, which includes the above Fréchet distribution as a special case. A special application of this result can be found in Kortum (1997) who develops an idea-based growth model where the limit distribution of productivities is Fréchet, with $T_{\omega, h}$ representing the stock of technological knowledge accumulated by supplier $\omega$ in category $h$.

Given the vector of effective prices, the representative consumer in county $i$ (who is endowed with income $Y_{i}$ ) maximizes her effective consumption, $\tilde{q}_{i, h}(v)=$ $\frac{\beta_{h} Y_{i}}{\tilde{p}_{i, h}(v)}$, by sourcing good $v$ from the cheapest provider. This amounts to solving the following discrete choice problem for each good $v$ :

$$
\tilde{p}_{i, h}(v)=\min _{\omega}\left\{\tilde{p}_{\omega i, h}(v)\right\}
$$

Defining $\alpha_{h} \equiv \theta_{h} / \vartheta_{h}$, the theorem of "general extreme value" implies that the 
share of goods purchased from firm $\omega$ in country $j$ is given by the following equation-a result we formally establish in Appendix A.

$$
\lambda_{\omega i, h}=\left(\frac{p_{\omega i, h} / \phi_{\omega, h}}{P_{j i, h}}\right)^{-\frac{\theta_{h}}{\alpha_{h}}}\left(\frac{P_{j i, h}}{P_{i, h}}\right)^{-\theta_{h}}
$$

where $\phi_{\omega, h} \equiv T_{\omega, h}^{\alpha_{h} / \theta_{h}}, P_{j i, h} \equiv\left[\sum_{\omega^{\prime} \in \Omega_{j i, h}}\left(p_{\omega^{\prime} i, h} / \phi_{\omega^{\prime} i, h}\right)^{-\frac{\theta_{h}}{\alpha_{h}}}\right]^{-\frac{\alpha_{h}}{\theta_{h}}}$, and $P_{i, h} \equiv\left[\sum_{k=1}^{N}\left(P_{k i, h}\right)^{-\theta_{h}}\right]^{-\frac{1}{\theta_{h}}}$. Altogether, total sales of firm $\omega \in \Omega_{j i, h}$ to market $i$, in product category $h$ can be calculated as:

$$
\begin{aligned}
x_{\omega i, h} & =p_{\omega i, h} q_{\omega i, h}=p_{\omega i, h} \lambda_{\omega i, h} \frac{X_{i, h}}{p_{\omega i, h}}=\lambda_{\omega i, h} X_{i, h} \\
& =\left(\frac{p_{\omega i, h} / \phi_{\omega i, h}}{P_{j i, h}}\right)^{-\frac{\theta_{h}}{\alpha_{h}}}\left(\frac{P_{j i, h}}{P_{i, h}}\right)^{-\theta_{h}} \beta_{h} Y_{i} .
\end{aligned}
$$

Manipulating the above equation and noting that $\lambda_{\omega \mid j, h}=\left(\frac{p_{\omega i, h} / \phi_{\omega i, h}}{P_{j i, h}}\right)^{-\frac{\theta_{h}}{\alpha_{h}}}$, results in the following import demand function

$$
x_{\omega i, h}=\Psi_{i, h}\left(\frac{p_{\omega i, h}}{\phi_{\omega, h}}\right)^{-\theta_{h}}\left(\lambda_{\omega \mid j, h}\right)^{1-\alpha_{h}}
$$

where $\Psi_{i, h} \equiv P_{i, h}^{\theta_{h}} \beta_{h} Y_{i}$. Notice that the above import demand function is identical to the one we derived under the variety-based framework, with one important qualification. In the above equation, $\phi_{\omega, h}$ represents the stock of qualityenhancing technological knowledge rather than actual quality, and $\alpha_{h}$ reflects the degree of national technology (rather than product) differentiation. We can summarize the above result alongside that from the previous section as follows.

Proposition 1. In both idea-based and variety-based trade models, the import demand function takes the following parametric structure

$$
\ln x_{\omega i, h}=-\theta_{h} \ln p_{\omega i, h}+\left(1-\alpha_{h}\right) \ln \lambda_{\omega \mid j i, h}+\Psi_{i, h}+\phi_{\omega i, h}
$$

where $x_{\omega i, h}$ and $p_{w i, h}$ denote, respectively, the sales and the unit price of a firm-specific variety $\omega$ exported from origin country $j$ to market $i$ in product category $h ; \ln \lambda_{\omega \mid j, h}=$ $x_{\omega, h} / \sum_{\omega^{\prime} \in \Omega_{j i, h}} x_{\omega^{\prime}, h}$ denotes the within-national market share of variety $\omega$ in market $i$; and $\Psi_{i, h} \equiv \ln P_{i, h}^{\theta_{h}} \beta_{h} Y_{i}$ denotes product-market fixed effects. 
Proof. See Appendix.

In Section 4, we will use the universal import demand function described by the above proposition to estimate parameters $\theta$ and $\alpha$. Next, however, we explore the general equilibrium implications of the above import demand function. In summary, we show that once the above import demand function is placed into a general equilibrium environment, parameter $\alpha$ regulates the degree of aggregate returns to scale, and parameter $\theta$ appears as the trade elasticity. Additionally, as long as a set of primitive general equilibrium conditions are satisfied, the above import demand function implies a unique formula for the gravity equation and the gains from trade-both of which are governed solely by structural parameters $\alpha$ (the scale elasticity) and $\theta$ (the trade elasticity). We lay out these arguments formally in the following section.

\subsection{From Partial to General Equilibrium}

In the previous section, we established that (given the set of exporting firms and firm-specific prices) the idea- and variety-based trade models deliver the same universal import demand function. Given its partial equilibrium nature, the universal import demand function was derived without imposing much structure on the supply side of the economy. Below, we argue that if the supply side of the economy satisfies a set of primitive conditions, the variety- and idea-based trade models also imply the same universal formula for the gravity equation and the gains from trade.

Suppose that the supply side of the economy satisfies the three primitive assumptions outlined in Arkolakis et al. (2012): (i) one factor of production (namely, labor with $L_{j}$ denoting the size of the labor force in country j); (ii) linear cost functions; and (iii) perfect or monopolistic competition. In addition to these assumptions, we impose two restrictions. First, we assume that firms are symmetric: for any two firms $\omega$ and $\omega^{\prime}$ from country $i, \phi_{\omega, h}=\phi_{\omega^{\prime}, h}=\phi_{i h}$ and $c_{\omega, h}=c_{\omega, h^{\prime}}=c_{i, h}$, where $c_{i, h}$ denotes the variable unit labor cost. Second, we assume that the number of firms is proportional to the share of labor employed in product category $h: N_{i, h} \propto L_{i, h}$. Both of these assumptions are trivially satisfied in the variety-based Krugman model with free entry; Ramondo et al. (2016) provide a discussion of why the latter restriction is economically sensible in idea-based models.

Given the above assumptions, the universal import demand function de- 
scribed by Equations 8 and 10 implies that total sales of country $j$ to $i$ in product category $h$ (i.e., $X_{j i, h} \equiv N_{j, h} x_{\omega, h}$ ) are described by the following gravity equation:

$$
X_{j i, h}=\frac{\psi_{j, h} L_{j, h}^{\alpha_{h}}\left(\tau_{j i} w_{j}\right)^{-\theta_{h}}}{\sum_{k=1}^{N} \psi_{k, h} L_{k, h}^{\alpha_{h}}\left(\tau_{k i} w_{k}\right)^{-\theta_{h}}} X_{i, h},
$$

where $L_{j, h}$ denotes the number of country $j$ workers employed in product category $h ; w_{i}=Y_{i} / L_{i}$ denotes labor wage in country $i ; \tau_{j i}$ denotes the iceberg transport cost; and $\psi_{j, h} \equiv\left(c_{i, h} \phi_{i, h}\right)^{\theta_{h}}$. The above gravity equation highlights the role of $\alpha_{h}$ as the scale elasticity. The higher $\alpha_{h}$ the larger the returns to expansion in product category or sector $h$. Put differently, the nominal number of suppliers, $N_{j, h} \propto L_{j, h}$, increases proportionally with the size of the labor force, whereas the effective number of suppliers, $\tilde{N}_{j, h} \propto L_{j, h^{\prime}}^{\alpha_{h}}$ increases more- or lessthan-proportionally depending on $\alpha_{h}$ (this feature relates to Patterns 1.A and 1.B from Section 2).

Overall, the above gravity equation nests the perfectly competitive gravity equations in Armington and Eaton and Kortum (2002) as a special case where $\alpha_{h}=0$, and nests the Krugman (1980) gravity equation as a special case where $\alpha_{h}=1$. As noted in Kucheryavyy et al. (2015), the existence and uniqueness of the trading equilibrium when the gravity equation takes the above functional form is a non-trivial matter. However, the autarky equilibrium is unique, and the gains from trade relative to autarky (starting from the factual equilibrium) are uniquely determined.

Using the universal import demand function we produced earlier, we can easily derive a formula for the gains from trade. In particular, the universal import demand function entails that $\lambda_{i i, h}=\left(P_{i i, h} / P_{i, h}\right)^{-\theta_{h}}$. The general equilibrium restrictions outlined above entail that $P_{i i, h}=c_{i, h} w_{i}\left(\phi_{i, h} L_{i, h}^{\alpha_{h} / \theta_{h}}\right)^{-1}$. Combining these two equations implies the following:

$$
\lambda_{i i, k}=c_{i, h}^{-\theta_{h}}\left(\phi_{i, h} L_{i, k}^{\alpha_{h} / \theta_{h}}\right)^{\theta_{h}} w_{i}^{-\theta_{h}} P_{i, h}^{\theta_{h}} .
$$

Given the CES structure of the import demand system, if follows that $W_{i, h}=$ $\zeta_{i, h} \frac{w_{i}}{P_{i, h}}$, where $\zeta_{i, h}$ is a function of, and only of, structural parameters. Hence, the above equation can be rearranged as

$$
W_{i, h}=\gamma_{i, h}\left[\left(L_{i, h}\right)^{\alpha_{h}} \lambda_{i i, h}\right]^{-\frac{1}{\theta_{h}}},
$$


where $\gamma_{i, h} \equiv \zeta_{i, h} / c_{i, h}$. For any factual value $z$, define $\hat{z} \equiv z / z^{A}$ where $z^{A}$ denotes the counterfactual autarky value of variable $z$. The above equation therefore implies that country $i^{\prime}$ s factual welfare relative to autarky is described by $\hat{W}_{i, h}=\left(\hat{\lambda}_{i i, h} \hat{L}_{i, h}^{\alpha_{h}}\right)^{-1 / \theta_{h}}$. Noting that $\lambda_{i i, h}^{A}=1, L_{i, h}=r_{i, h} L_{i}$, and $r_{i, h}^{A}=\beta_{i, h}$ (where $r_{i, h}$ denotes the share of country $i$ 's revenue generated in product category $h$ ), the gains from trade relative to autarky will be characterized by the following equation:

$$
\hat{W}_{i}=\prod_{h \in H} \hat{W}_{i, h}^{\beta_{i, h}}=\prod_{h \in H}\left(\lambda_{i i, h}\left(\frac{\beta_{i, h}}{r_{i, s}}\right)^{\alpha_{h}}\right)^{-\frac{\beta_{i, h}}{\theta_{h}}}
$$

The above gains-from-trade formula is a trivial extension of the Arkolakis et al. (2012) formula. Nonetheless, it displays an attractive property: it depends only on parameters $\alpha_{h}$ and $\theta_{h}$, both of which can be estimated using the structural import demand function characterized by Proposition 1. Once $\alpha_{h}$ and $\theta_{h}$ are identified, the gains from trade can be uniquely calculated using product- or sector-level data on factual trade shares, $\lambda_{i i, h}$, revenue shares, $r_{i, s}$, and expenditure shares, $\beta_{i, h}$. We can summarize the above arguments as follows.

Proposition 2. In an economy characterized by the import demand function in Equation 11, if a set of primitive general equilibrium conditions are satisfied, the gains from trade relative to autarky are uniquely determined, and given by

$$
\hat{W}_{i}=\frac{W_{i}}{W_{i}^{A}}=\prod_{h \in H}\left[\lambda_{i i, h}\left(\frac{\beta_{i, h}}{r_{i, h}}\right)^{\alpha_{h}}\right]^{\frac{\beta_{i, h}}{\theta_{h}}},
$$

where $\theta_{h}$ (the trade elasticity) and $\alpha_{h}$ (the scale elasticity) are structural parameters pertaining to the import demand function; $\lambda_{i i, h}, r_{i, h}$ and $\beta_{i, h}$ denote the trade, revenue, and expenditure shares in country $i$, product category $h$, respectively.

To take stock, we have derived an import demand function that underlies two distinct and important class of trade models (Proposition 1). Estimating the import demand function, which is plausible with standard customs data, delivers two structural parameters: the scale elasticity, $\alpha_{h}$, and the trade elasticity, $\theta_{h}$. Once these two parameters are pinned down, the gains from trade are uniquely determined given data on factual trade, revenue and expenditure shares (Proposition 2).

The following two sections explore these two empirical directions. First, we estimate the universal import demand function described by Proposition 1 using micro-level trade data. Second, building on Proposition 2, we employ 
the estimated parameters from step one to calculate the gains from trade with sectoral trade and production data.

\section{Estimation}

In this section we use the universe of Colombian import transactions from 2007-2013 to estimate the structural import demand function described by Proposition 1. First, we perform a pooled estimation that restricts the scale and trade elasticities to be uniform across all product categories. Under uniform elasticities, our estimated equation can be written as

$$
\ln x_{\omega, h t}=-\theta \ln p_{\omega, h t}+(1-\alpha) \ln \lambda_{\omega \mid j, h t}+\Psi_{h t}+\bar{\phi}_{\omega, h}+\varepsilon_{\omega, h t},
$$

where $\alpha$ and $\theta$ could be perceived as the economy-wide scale and trade elasticities. The importer subscript is dropped as we are focusing on a single importer, and subscript $t$ is included to account for the time dimension of our data. Considering the structure of our data set, variety " $\omega, h t$ " corresponds to an imported variety sourced from firm $\omega$ located in country of origin $j$, within HS10 product category $h$, in year $t$. For every imported variety, $\omega, h t$, we observe total sales $\left(x_{\omega, h t}\right)$, unit price $\left(p_{\omega, h t}\right)$, and we can calculate the within-national market share as:

$$
\lambda_{\omega \mid j, h t}=\frac{x_{\omega, h t}}{\sum_{\omega^{\prime} \in \Omega_{j i, h t}} x_{\omega^{\prime}, h t}}
$$

The term $\Psi_{h t}$ denotes a product-year fixed effect that is composed of the productwide price index and total expenditure; and $\bar{\phi}_{\omega, h}$ is a firm-product fixed effect that reflects the actual quality or the stock of quality-enhancing knowledge specific to firm $\omega$ in product category $h$. Finally, $\varepsilon_{\omega, h t}$ is an unobservable demand shifter that reflects the idiosyncratic variations in quality, measurement errors, or non-technological demand shifters specific to variety $\omega, h t$. Altogether, our estimated equation closely resembles the nested demand function analyzed in Berry (1994). However, given the structure of our data, we adopt a distinct identification strategy.

Before presenting our estimation strategy, we highlight the types of variation in the data that identify parameters $\theta$ and $\alpha$. The trade elasticity, $\theta$, is identified by looking at the variation in export sales and unit prices across firms. The identification of the scale elasticity, $\alpha$, is best understood considering that the scale elasticity reflects the degree of national product/technology differen- 
tiations. Broadly speaking, a variety is either imported from a crowded source, like China, where it is one of the many imported Chinese varieties (hence, a low $\left.\lambda_{\omega \mid j, h t}\right)$; or it is imported from a less-crowded source, like Taiwan, where it is one of the few imported varieties from that country (hence, a high $\lambda_{\omega \mid j, h t}$ ). Conditional on unit prices, if varieties from crowded sources generate lower sales the above import demand function identifies this as a case where $1>\alpha>0$-i.e., varieties are nationally differentiated so consumers discount low $-\lambda_{\omega \mid j, h}$, varieties coming from crowded sources. By contrast, if consumers do not discount varieties imported from crowded sources, the import demand function identifies this as $\alpha=1$.

To estimate Equation 13, we employ a first-difference estimator that eliminates the firm-product fixed effect, $\bar{\phi}_{\omega, h}$, and drops observations pertaining to one-time exporters. We deem the first-difference approach appropriate given that the $\varepsilon_{\omega, h t} \mathrm{~S}$ are possibly sequentially correlated. Stated in terms of firstdifferences, our estimating equation takes the following form

$$
\Delta \ln x_{\omega, h t}=-\theta \Delta \ln p_{\omega, h t}+(1-\alpha) \Delta \ln \lambda_{\omega \mid j, h t}+\Delta \Psi_{h t}+\tilde{\varepsilon}_{\omega, h t} .
$$

where $\tilde{\epsilon}_{\omega, h t} \equiv \Delta \epsilon_{\omega, h t}$ and $\Delta \Psi_{h t}$ can be treated as a product-year fixed effect, which controls for $(i)$ product-specific inflation and $(i i)$ growth in national expenditure on product $h$.

Estimating equation 14, we need to address the endogeneity of price and within-national market share-both variables may be endogenous to variations in the demand shifter, $\tilde{\epsilon}_{\omega, h t} \cdot{ }^{11}$ While the first-difference transformation is a partial remedy, to identify the price and within-national market share coefficients we construct firm-specific instruments for both variables.

For unit prices, we construct two plausibly exogenous instruments in the style of Bartik (1991)—namely, trade-weighted exchange rates and import taxes, both of which utilize monthly variations in the data. In particular, we compile a data set on monthly variations in national exchange rates, and combine it with the monthly variation in firm-product specific sales. By virtue of doing so, we can construct trade-weighted annual exchange rates that are variety-specific:

\footnotetext{
${ }^{11}$ Note that the within-national market share, $\lambda_{\omega \mid j, h t}$, could be correlated with $\varepsilon_{\omega, h t}$ due to measurement errors in export sales. Our identification strategy takes care of this alternative source of endogeneity as long as our instruments are not correlated with variety-specific measurement errors. Similarly, unit prices could be contaminated with measurement errors, as they are averaged across transactions and consumers. This type of measurement error, however, is fairly innocuous, given the log-linear structure of our demand function (see Berry (1994)).
} 
$E_{\omega, h t}=\frac{\sum_{m \in t} E_{j, m} x_{\omega, h m}}{\sum_{m \in t} x_{\omega, h m}}$, where $m$ denotes a month pertaining to year $t$ and $\omega$ denotes a firm located in country $j$. Effectively, firms from the same country of origin face different exchange rates depending on the months of the year in which they export. Similarly, we can construct a trade-weighted annual import tax rate per imported variety. Trade taxes, which include tariffs and value added tax, vary not only monthly but also across firms within the same product-origin country-year. $^{12}$

Figure 2 illustrates the workings of our instruments. The example corresponds to U.S. exports in product category HS8431490000 (PARTS AND ATTACHMENTS OTHER FOR DERRIKS ETC.). This is a product category that features one of the most frequently imported varieties-namely, machine parts from CATERPILLAR. The left panel of Figure 2 displays how both the exchange rate and the average import tax paid by U.S. based firms vary considerably on a monthly basis in 2009. The right panel plots monthly variations in the export activity of the two largest U.S. based firms within category HS8431490000, in year 2009 (namely, CATERPILLAR and MACHINERY CORP. OF AMERICA). Given their markedly different export patterns, CATERPILLAR and MACHINERY CORP. OF AMERICA face effectively different exchange rates and pay different import taxes. We utilize these across-variety differences as an arguably exogenous source of variation in export prices.

Regarding the within-national market share, $\lambda_{\omega \mid j, h t}$, we adopt instruments that are similar to those suggested by Khandelwal (2010). In particular, we instrument for within-national market share with (i) the number of firms exporting from country $j$ in product category $h$ and (ii) the total number of product categories in which the firm supplying variety $\omega$ is an active exporter (within year $t)$.

Our second specification estimates a sector-wide trade elasticity, $\theta_{s}$, and scale elasticity, $\alpha_{s}$. Here, $s$ indexes a sector that is comprised of multiple HS10 product categories. We pool all HS10 products that belong to the same sector $s$ (i.e., $h \in H_{s}$ ), and estimate the import demand function separately for each of

\footnotetext{
${ }^{12} \mathrm{We}$ check the robustness of our results using an alternative instrument for price, which is motivated by Hausman's "other price" approach. Specifically, we instrument for $p_{\omega, h t}$, with the average price charged by the firm supplying variety $\omega$ in other years within other HS10 product categories. The estimation results reported in the next section are produced using both trade-weighted import tax and exchange rates as instruments. However, all the estimates remain qualitatively the same when we instead employ each instrument separately or use the additional "other price" instrument.
} 
Figure 2: Monthly variations in national exchange rate, firm-specific exports, and import tax within a selected product-country-year category.
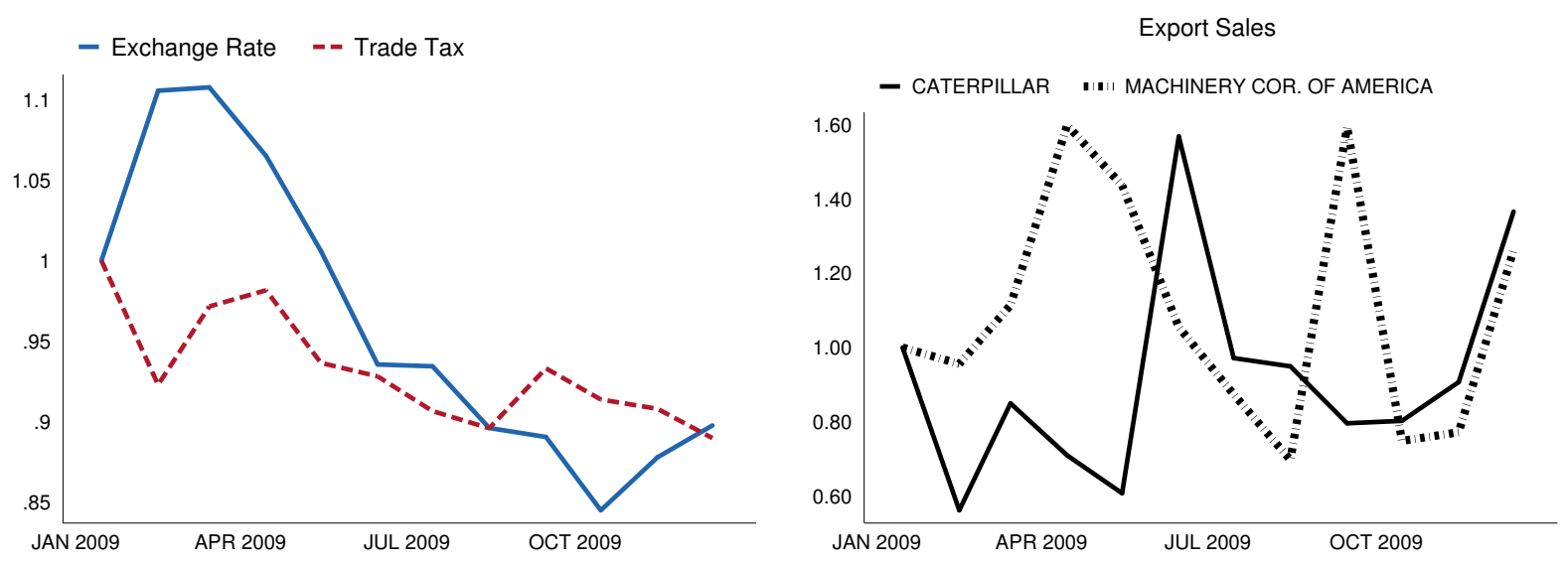

Note: The left panel plots monthly variations in exchange rate and (value-weighted) average import tax for US-based firms within product category HS8431490000-year 2009. The right panel plots monthly movements in export sales for the two biggest US firms in product HS8431490000-year 2009 - namely, Caterpillar and Machinery Corp. of America.

the 12 sectors in our sample: ${ }^{13}$

$$
\Delta \ln x_{\omega, h t}=-\theta_{s} \Delta \ln p_{\omega, h t}+\left(1-\alpha_{s}\right) \Delta \ln \lambda_{\omega \mid j, h t}+\tilde{\Psi}_{h t}+\tilde{\varepsilon}_{\omega, h t}
$$

Note that, in principle, we can also estimate the import demand function separately for each HS10 product category. We opt, however, for elasticities estimated at the sector-wide level for a practical reason. Our goal is to incorporate our estimates into the gains from trade formula, which requires data on trade, revenue, and expenditure shares. Since this data is available only at the sectorlevel, we simply need sector-wide elasticities to compute the gains from trade.

Results. The results corresponding to the pooled estimation (Equation (14)) are reported in Table 4 . The estimation implies an economy-wide scale elasticity of $\alpha \approx 0.6$. Given that $\alpha<1$, the estimation essentially rejects the independence of irrelevant alternatives (IIA). Put differently, $\alpha<1$ indicates that products or technologies are relatively more similar intra-nationally than internationally. However, the degree of national product/technology differentiation is not as extreme as assumed in competitive trade models (e.g., Anderson and Van Wincoop (2003); Eaton and Kortum (2002)) where $\alpha=0$. Additionally, our estimation suggests that products and technologies are more nationally differ-

\footnotetext{
${ }^{13}$ Sector groupings are defined according to http://www.foreign-trade.com/ reference/hscode. htm. We focused only on manufacturing sectors.
} 
Table 4: Import Demand Estimation

\begin{tabular}{lcccccc}
\hline & \multicolumn{2}{c}{ Manufacturing } & & \multicolumn{2}{c}{ Non-Manufacturing } \\
\cline { 2 - 3 } \cline { 7 - 7 } Variable $(\log )$ & IV & OLS & & IV & OLS \\
\hline Price, $-\theta_{2}$ & $-1.876^{* * *}$ & $0.069^{* * *}$ & & $-3.072^{* * *}$ & $0.031^{* * *}$ \\
& $(0.059)$ & $(0.000)$ & & $(0.253)$ & $(0.001)$ \\
National export share, $1-\frac{\theta_{2}}{\theta_{1}}$ & $0.397^{* * *}$ & $0.884^{* * *}$ & & $0.203^{* * *}$ & $0.857^{* * *}$ \\
& $(0.009)$ & $(0.000)$ & & $(0.033)$ & $(0.001)$ \\
Observations & & & & & \\
R-squared & $1,138,135$ & $1,138,135$ & & 207,192 & 207,192 \\
& $\ldots$ & 0.82 & & $\ldots$ & 0.76
\end{tabular}

Notes: Estimation results of Equation (14). Robust standard errors in parentheses. ${ }^{*}$ significant at $10 \%$; ${ }^{* *}$ significant at $5 \% ;{ }^{* * *}$ significant at $1 \%$. The estimation is conducted with HS10 product-year fixed effects. The reported $R^{2}$ correspond to within-group goodness of fit.

entiated in manufacturing sectors. Similar arguments apply to our sector-wide elasticity estimates.

The sector-wide estimates, corresponding to Equation (15), are reported in Table 5. The estimated elasticities display a considerable amount of inter-sectoral variation. Furthermore, with the exception of Wood Products and Stone/Glass, we cannot reject the prevalence of national differentiation, which is most pronounced in the Transportation and Plastics/Rubbers sectors. Our estimated trade elasticities $\left(\theta_{2, s}\right)$, meanwhile, are slightly lower than those estimated in Caliendo and Parro (2014) and Simonovska and Waugh (2014). This outcome is expected, since $(i)$ we are exploiting within-HS10 product-year, across-firm variations rather than within-sector, cross-national variations, and (ii) we are estimating a less-parametric import demand function that does not restrict the scale elasticity.

\subsection{Discussion}

As noted earlier, the estimated scale elasticity $(\alpha)$ reflects the degree of national product/technology differentiation and regulates sector-wide scale economies. This is evident from the gravity Equation 12, where a higher $\alpha$ implies a stronger link between scale $\left(L_{j, h}\right)$ and international sales $\left(X_{j i, h}\right)$. Pooling all manufacturing sectors, we estimate a uniform economy-wide scale elasticity of $\alpha \approx 0.6$. To put this number in perspective, note that competitive trade models (e.g., Eaton and Kortum (2002); Anderson (1979)) often set $\alpha=0$, whereas imperfectly com- 
Table 5: Import Demand Estimation by Sector

\begin{tabular}{|c|c|c|c|c|}
\hline \multirow[b]{2}{*}{ Sector } & \multirow[b]{2}{*}{ HS2 codes } & \multicolumn{2}{|c|}{ Estimated Parameter } & \multirow[b]{2}{*}{ Observations } \\
\hline & & $\theta_{2}$ & $1-\alpha$ & \\
\hline Chemicals & $28-38$ & $\begin{array}{c}2.099 * * * \\
(0.158)\end{array}$ & $\begin{array}{c}0.173^{* * *} \\
(0.022)\end{array}$ & 60,782 \\
\hline Plastics/Rubbers & $39-40$ & $\begin{array}{c}2.749 * * * \\
(0.295)\end{array}$ & $\begin{array}{c}0.285^{* * *} \\
(0.050)\end{array}$ & 120,733 \\
\hline Leather & $41-43$ & $\begin{array}{c}2.229 * * * \\
(0.361)\end{array}$ & $\begin{array}{c}0.250 * * * \\
(0.076)\end{array}$ & 14,839 \\
\hline Wood Products & $44-49$ & $\begin{array}{c}6.576^{* * *} \\
(2.521)\end{array}$ & $\begin{array}{c}0.052 \\
(0.190)\end{array}$ & 40,491 \\
\hline Textiles & $50-63$ & $\begin{array}{c}2.030^{* * *} \\
(0.124)\end{array}$ & $\begin{array}{c}0.359^{* * *} \\
(0.016)\end{array}$ & 101,991 \\
\hline Footwear/Headgear & $64-67$ & $\begin{array}{c}4.663^{* * *} \\
(0.847)\end{array}$ & $\begin{array}{l}0.212^{* *} \\
(0.099)\end{array}$ & 18,821 \\
\hline Stone/Glass & $68-71$ & $\begin{array}{c}4.427^{* * *} \\
(0.853)\end{array}$ & $\begin{array}{c}0.080 \\
(0.119)\end{array}$ & 32,801 \\
\hline Metals & $72-83$ & $\begin{array}{c}3.277^{* * *} \\
(0.289)\end{array}$ & $\begin{array}{c}0.332^{* * *} \\
(0.039)\end{array}$ & 160,299 \\
\hline Machinery/Electrical & $84-85$ & $\begin{array}{c}3.849 * * * \\
(0.241)\end{array}$ & $\begin{array}{c}0.158^{* * *} \\
(0.035)\end{array}$ & 471,805 \\
\hline Transportation & $86-89$ & $\begin{array}{c}0.446^{* * *} \\
(0.064)\end{array}$ & $\begin{array}{c}0.719 * * * \\
(0.013)\end{array}$ & 63,760 \\
\hline Instruments & $90-93$ & $\begin{array}{c}0.833^{* * *} \\
(0.113)\end{array}$ & $\begin{array}{c}0.375^{* * *} \\
(0.022)\end{array}$ & 91,044 \\
\hline Miscellaneous & $94-96$ & $\begin{array}{c}3.305^{* * *} \\
(0.417)\end{array}$ & $\begin{array}{c}0.010 \\
(0.091)\end{array}$ & 62,905 \\
\hline
\end{tabular}

Notes. Estimation results of Equation (15). Robust standard errors in parentheses. * significant at $10 \% ; * *$ significant at $5 \%$; ** significant at $1 \%$. The estimation is conducted with HS10 product-year fixed effects. Sector groupings are defined according to http: //www. foreign-trade.com/reference/hscode.htm. 
Table 6: Scale Elasticity in Mainstream Trade Models.

\begin{tabular}{ccc}
\hline \multirow{2}{*}{ Estimation } & \multicolumn{2}{c}{ Canonical Trade Models } \\
\cline { 2 - 3 } & $\begin{array}{c}\text { Armington, } \\
\text { Eaton-Kortum 2002 }\end{array}$ & $\begin{array}{c}\text { Krugman, Melitz, } \\
\text { Eaton-Kortum 2001 }\end{array}$ \\
\hline$\alpha=0.6$ & $\alpha=0$ & $\alpha=1$ \\
\hline
\end{tabular}

petitive models (e.g., Krugman (1980); Eaton and Kortum (2001); Melitz (2003)) impose $\alpha=1$. Table 6 compares our estimated elasticity to these standard normalizations.

Altogether, our estimates suggest that scale effects are quantitatively significant but weaker than generally assumed in "New" trade theories. Expectedly, this finding has sharp aggregate implications, which we review in the next section. Meanwhile, the sector-wide scale elasticities are far from uniform and display considerable sectoral variation. These variations, which are often overlooked in quantitative trade models, are foundational to the estimated gains from trade. In the next section, we also revisit this issue by estimating gains from trade while accounting for sectoral variations in the scale elasticity.

Importantly, our analysis provides an empirical basis for discriminating between two classic but competing views of intra-industry trade. The first one is the so-called biological view, where nationally differentiated products or technologies arise in response to peculiarities in local demand (Bhagwati (1982); Feenstra (1982)). This view corresponds to an $\alpha$ that is closer to zero. The second one is the popular view that intra-industry trade is driven by increasing returns to scale (Krugman (1980)). This latter view is more relevant the closer $\alpha$ is to one. Considering our results in Table 5, we estimate a greater role for aggregate returns to scale in most sectors. Nonetheless, with the exception of a few sectors, national differentiation is an economically significant force. These findings complement previous attempts to discriminate between these two views with more aggregated data (e.g., Head and Ries (2001)).

Finally, our estimates lend themselves to alternative and possibly broader interpretations of scale effects. Kucheryavyy et al. (2015) establish that a model featuring Marshallian externalities is isomorphic to the multi-sector varietybased model we used to estimate the scale elasticities. Extrapolating our results to an environment featuring external scale economies, our estimated scale elasticities could reflect returns to agglomeration. Intuitively, our estimation con- 
trols for the number of varieties and nominal price and finds that varieties from crowded sources are discounted by consumers. These findings, therefore, suggest that benefits from local spillovers may be diminishing, as firms are more similar to their local rivals in terms of the ideas or products they develop.

\section{General Equilibrium Analysis}

This section discusses the general equilibrium implications of our micro-level estimates. First, we compute the gains from trade implied by our sector-specific elasticity estimates. Second, we calibrate a multi-country gravity model featuring scale economies that are consistent with our micro-level estimates and demonstrate how this adjustment enhances the model's predictive power.

\subsection{Sectoral Specialization and Welfare}

Our estimates have sharp implications for the international allocation of the gains from trade. Theoretically, it is well-understood that the gains from trade are highly sensitive to sectoral variations in the scale elasticity (Kucheryavyy et al. (2015); Costinot and Rodríguez-Clare (2014)). However, given the lack of micro-level estimates, the existing literature typically overlooks these variations by normalizing the scale elasticity, $\alpha$, to either 0 or 1 . We take a first step towards relaxing these normalizations, which are decisive to the distribution of the gains from trade across countries.

Given Proposition 2, we can write the gains from trade formula in terms of sector-wide elasticities and statistics as follows:

$$
\hat{W}_{i}=\prod_{s}\left[\lambda_{i i, s}\left(\frac{\beta_{i, s}}{r_{i, s}}\right)^{\alpha_{s}}\right]^{\frac{\beta_{i, s}}{\theta_{s}}},
$$

where $s$ denotes a sector for which we have data on $\beta_{s}, r_{i, s}$ and $\lambda_{i i, s}$ from the world input-output database (WIOD). Overall, the data set covers 32 sectors and 34 countries. In the previous section, we estimated $\theta_{s}$ and $\alpha_{s}$ for 11 of manufacturing sectors in the WIOD sample. Following Costinot and RodríguezClare (2014), we normalize $\theta_{s}$ to 100 and the scale elasticity, $\alpha_{s}$, to zero for the non-traded or non-manufacturing sectors. The computed gains from trade are reported in Table 7. Additionally, Table 7 reports the gains implied by two standard normalizations: (i) the EK-Armington normalization, where $\alpha_{s}=0$ for all 
manufacturing sectors, and (ii) the Krugman normalization, where $\alpha_{s}=1$ for all manufacturing sectors.

In summary, the overall size of the gains from trade is fairly similar across all specifications, whereas the international allocation of the gains differs systematically. This finding resonates with the arguments in Costinot and RodríguezClare (2014) and Kucheryavyy et al. (2015) that the gains from trade favor (i) countries with higher degrees of specialization and (ii) countries that specialize in high- $\alpha$ sectors with stronger returns to scale. In fact, these assertions have deep historical roots, but empirical explorations of such arguments have been impeded by a lack of micro-level estimates. We take a first stab at empirically isolating the role of sector-wide scale effects. To this end, we use our micro-level elasticity estimates to compute two national indexes identified by Kucheryavyy et al. (2015). The first one is an index that captures the overall degree of specialization: $\sum_{s} \beta_{s} \log \frac{\beta_{i, s}}{r_{i, s}}$. The second one is an index that captures the scale intensity of a country's specialization

$$
\text { Scale-Intensity }_{i}=\sum_{s}\left(\frac{\kappa_{s}-\bar{\kappa}}{\bar{\kappa}}\right) \beta_{s} \log \frac{\beta_{i, s}}{r_{i, s}},
$$

where $\kappa_{s} \equiv \frac{\alpha_{s}}{\theta_{s}}$ and $\bar{\kappa}=\frac{1}{32} \sum_{s=1}^{32} \kappa_{s}$ reflects the scale elasticity of the average sector. The scale intensity index adopts a larger value if a country generates relatively more revenue in sectors with stronger returns to scale. This index determines if a country gains more or less from trade. To demonstrate this, we calculate the gains from trade (implied by our estimated scale elasticities) net of standard gains implied by a model with no scale effects. Figure 3 plots the net gains against the scale intensity of the country's specialization. As expected, countries with more scale-intensive specialization gain relatively more from trade. For example, Korea and Taiwan experience relatively larger gains from trade, as they specialize in sectors with strong returns to scale. Greece and Russia, meanwhile, experience smaller gains due to their less scale-intensive pattern of specialization.

The intuition behind the above findings is straightforward. International trade induces production specialization, leading to the expansion of comparatively advantaged sectors in each country. In sectors where products or technologies are more similar intra-nationally (e.g., Stone/Glass, Wood Products, or non-manufacturing sectors) the industry-wide returns to specialization are smaller. Greece and Russia have a comparative advantage in these low-return 
Figure 3: The gains from trade $\times$ Scale-intensity of national specialization

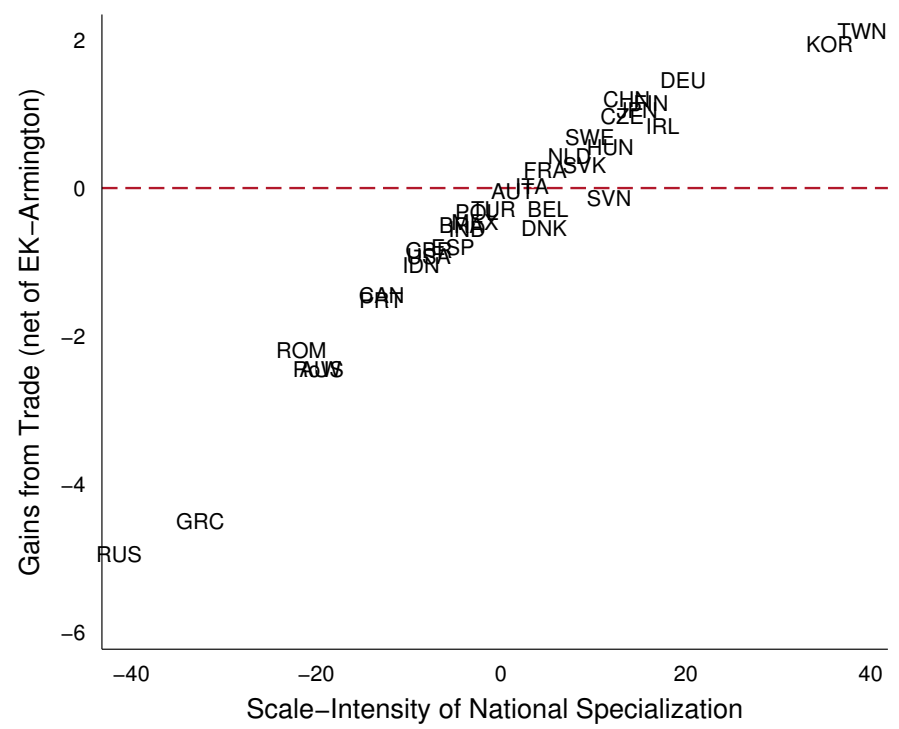

sectors, which effectively contracts their gains from trade. By contrast, sectors featuring greater degrees of intra-national differentiation (e.g., Chemicals and Machinery) are subject to greater returns to specialization. Korea, Taiwan and Germany have a comparative advantage in these high-return sectors and, therefore, benefit relatively more from trade-induced specialization.

\subsection{Population Size and Welfare}

Now we turn to the national size-income relationship, which is deep-rooted in standard gravity trade models. Since the following analysis requires only aggregate trade data, we extend our sample to include 101 countries. ${ }^{14}$ We calibrate to aggregate bilateral trade data a gravity model that features scale effects that are consistent with our economy-wide estimate of $\alpha$. We compare the explanatory power and the implications of this benchmark model to those of the standard Krugman model with normalized scale effects.

\subsubsection{Calibration procedure}

We calibrate a one-sector version of our model to match the bilateral trade shares for 101 countries. The calibration is performed in the following steps:

\footnotetext{
${ }^{14}$ We restrict our attention to 101 countries for which we have data on the stock of human capital in 2000 .
} 
i. Following the gravity equation described by Equation 12, trade shares are given by

$$
\lambda_{j i}=\frac{\psi_{j} L_{j}^{\alpha}\left(\tau_{j i} w_{j}\right)^{-\theta}}{\sum_{k=1}^{N} \psi_{k} L_{k}^{\alpha}\left(\tau_{k i} w_{k}\right)^{-\theta}} .
$$

ii. We use the data on $L_{j}$ (population size in country $j$ ), and impose the following parameterization of $T_{j}$ and $\tau_{j i}$ :

$$
\left\{\begin{array}{l}
\tau_{j i}=\beta_{1}\left(\operatorname{DIST}_{j i}\right)^{\beta_{2}} \\
\psi_{j}=b\left(H_{j}\right)^{\beta_{3}}
\end{array},\right.
$$

where DIST $_{j i}$ is the distance between countries $j$ and $i$, and $H_{j}$ denotes the stock of human capital in country $j$. Importantly, $H_{j}$ is not statistically correlated with population size, $L_{i}$. Hence, our calibration exercise is distinct from those of Alvarez and Lucas (2007) and Waugh (2010), who avoid strong scale effects by allowing technology levels to decrease rapidly with population size.

iii. For any given vector of parameters $\Theta=\left(\beta_{1}, \beta_{2}, \beta_{3}, \alpha\right)$, we can solve for a unique vector of wages $\left\{w_{j}\right\}_{j=1}^{N}$ that satisfies the balanced trade condition. Given the equilibrium wages, we can solve for the equilibrium trade shares.

iv. We search for a vector of parameters $\Theta$ that minimizes the distance between predicted trade shares and factual trade shares.

Note that while we choose $\alpha$ to fit aggregate trade patterns, we could alternatively calibrate it to the value implied by our micro-level estimation. Encouragingly, both approaches deliver qualitatively similar outcomes. ${ }^{15}$ Either way, our goal is to compare the benchmark model to a baseline model calibrated to the same data, but with a normalized scale elasticity of $\alpha=1$. The baseline, thus, corresponds to a range of canonical trade models, including Krugman (1980), Melitz (2003)/Chaney (2008), and Eaton and Kortum (2001). ${ }^{16}$ Henceforth, we refer to the baseline model as the Krugman-Melitz model.

\footnotetext{
${ }^{15}$ Choosing $\alpha$ to match aggregate trade values implies a scale elasticity strictly lower than one, which is consistent with our micro-level estimates. However, the calibrated elasticity is slightly below 0.6 , which is indicative of domestic trade frictions.

${ }^{16}$ The Melitz-Pareto model is isomorphic to the baseline specification. Specifically, suppose
} 


\subsubsection{Quantitative Implications}

Below, we analyze the effect of scale (i.e., population size) on aggregate economic outcomes from the perspective of the calibrated benchmark model and the baseline Krugman-Melitz model. Our analysis delivers three principal results, which we outline below.

National size and welfare. Normalizing the scale elasticity to one leads to non-diminishing returns to population size. Hence, a wide class of standard gravity models (featuring this normalization) predicts a counter-factually strong and positive relationship between population size and real per-capita income. For example, consider a standard Krugman or Melitz-Pareto model. The real income per worker in country $i\left(W_{i}\right)$ depends on national productivity, $T_{i}$, population size, $L_{i}$, and domestic expenditure share, $\lambda_{i i}$ :

$$
W_{i}=\gamma \times\left(T_{i} \cdot L_{i}\right)^{\frac{1}{\theta}} \times \lambda_{i i}^{-\frac{1}{\theta}}
$$

As Ramondo et al. (2016) point out, small countries import a higher share of their income (i.e., have a lower $\lambda_{i i}$ ), which partially mitigates their size disadvantage. However, after controlling for the observed levels of trade, the scale effects are still strong enough to imply a strong, positive relationship between population size and real income per worker. These arguments are illustrated in Figure 4 (bottom panel), which displays the positive size-income relationship predicted by the calibrated baseline Krugman-Melitz model.

The benchmark model, meanwhile, features scale effects that are consistent with our micro-level estimates. The real income per worker in the benchmark model is given by

$$
W_{i}=\gamma \times T_{i}^{\frac{1}{\theta}} \times L_{i}^{\frac{\alpha}{\theta}} \times \lambda_{i i}^{-\frac{1}{\theta}}
$$

Provided that $\alpha<1$, the benchmark model predicts a weaker effect of population size on real per capita income. In fact, as illustrated in Figure 4, the

the fixed cost of exporting is uniform across markets: $f_{j i}=f_{i}$. The Melitz-Pareto model then predicts the following trade share

$$
\lambda_{j i}=\frac{L_{j}\left(\tau_{j i} w_{j}\right)^{-\gamma} f_{j}^{\frac{\theta-\gamma}{\theta}}}{\sum_{k=1}^{N} L_{k}\left(\tau_{k i} w_{k}\right)^{-\gamma} f_{k}^{\frac{\theta-\gamma}{\theta}} .}
$$

The trade shares are therefore identical to our baseline model, with $T_{j}=f_{j}^{\frac{\theta-\gamma}{\theta}}$. 
benchmark model could near-exactly reproduce the factual, negative relationship between population size and real per-capita income. For example, consider a small rich country like Sweden. The benchmark model implies that Sweden's real per-capita income is $60 \%$ that of the United States, which is much closer to the actual $76 \%$ than the $30 \%$ predicted by the baseline Krugman-Melitz model. Theoretically, a weak income-size relationship could be driven by either a smaller-than-one $\alpha$ or domestic trade frictions. Empirically, both forces bear importance. Ramondo et al. (2016) show that even after controlling for direct measures of domestic trade frictions, the income-size relationship predicted by a Krugman-Melitz type model remains counter-factually strong.

National size and the gains from trade. Earlier, we established that sectoral variations in the scale elasticity are pivotal to the gains from trade. Here, we highlight how the economy-wide scale elasticity regulates the gains from trade in a one-sector trade model. To this end, we compute the gains from trade liberalization (i.e., moving from the factual equilibrium to free trade) using both the benchmark and baseline models. Compared to the baseline, the benchmark model predicts that the gains from trade liberalization are both smaller and less pro-small. Intuitively, free trade exposes countries to new technologies or products developed by foreign populations. In the baseline Krugman-Melitz model, free trade with partner $i$ exposes one to $L_{i}$ effectively new technologies or products. In the benchmark model, however, free trade with partner $i$ exposes one to $L_{i}^{\alpha}$ effectively new technologies or products (where $\alpha<1$ ). Hence, the benefits of trade with highly populated nations are relatively smaller in the benchmark model and relatively larger in the Krugman-Melitz model. Figure 5 displays these differences, which are computed using the two calibrated models.

Economic versus political integration. There is a vibrant body of literature on optimal country size, which analyzes the relative advantages of economic integration (free trade across political borders) compared to political integration (elimination of political borders)—see Alesina et al. (2000) or Alesina and Spolaore (2005). Our estimation contributes to this rather old discussion by highlighting one of the possible disadvantages of political integration. Specifically, in the baseline Krugman-Melitz model with normalized scale effects, political integration is isomorphic to economic integration. In the benchmark model where $\alpha<1$, however, returns to political integration are smaller. To elaborate, note that eliminating political borders (e.g., unifying the educational and po- 
Figure 4: Real wage $\times$ population size: data vs. model prediction.

Benchmark (adjusted scale effects)

- Predicted values

$\square$ Data

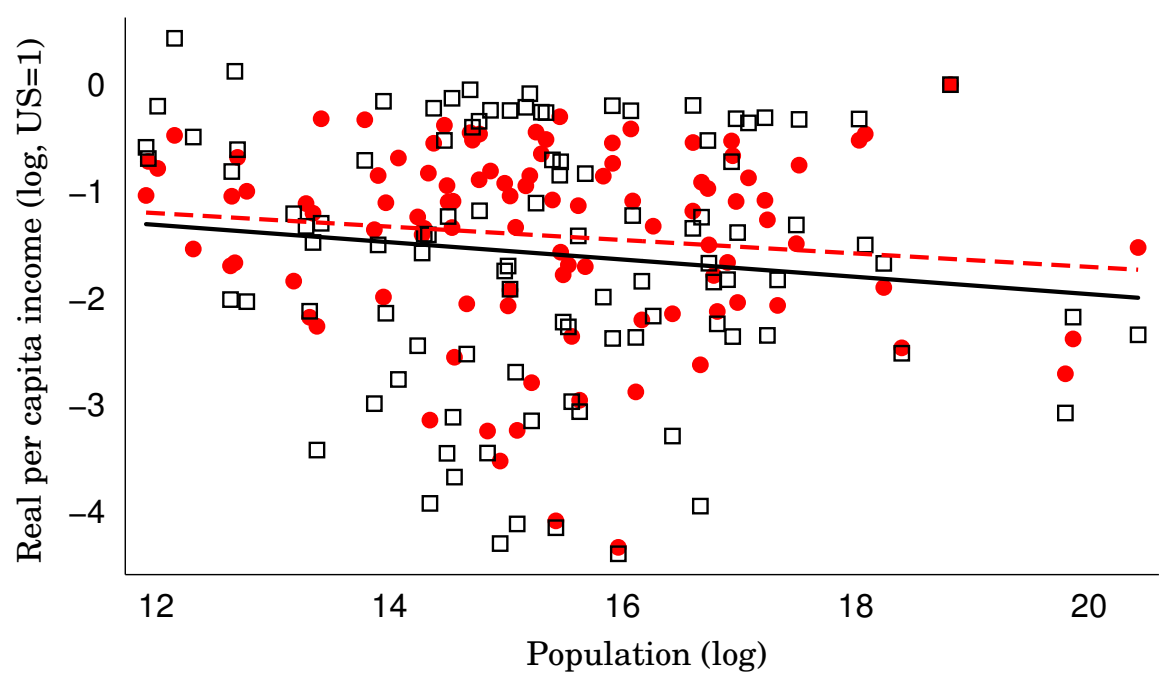

Krugman-Melitz

○ Predicted vlaues $\quad \square$ Data

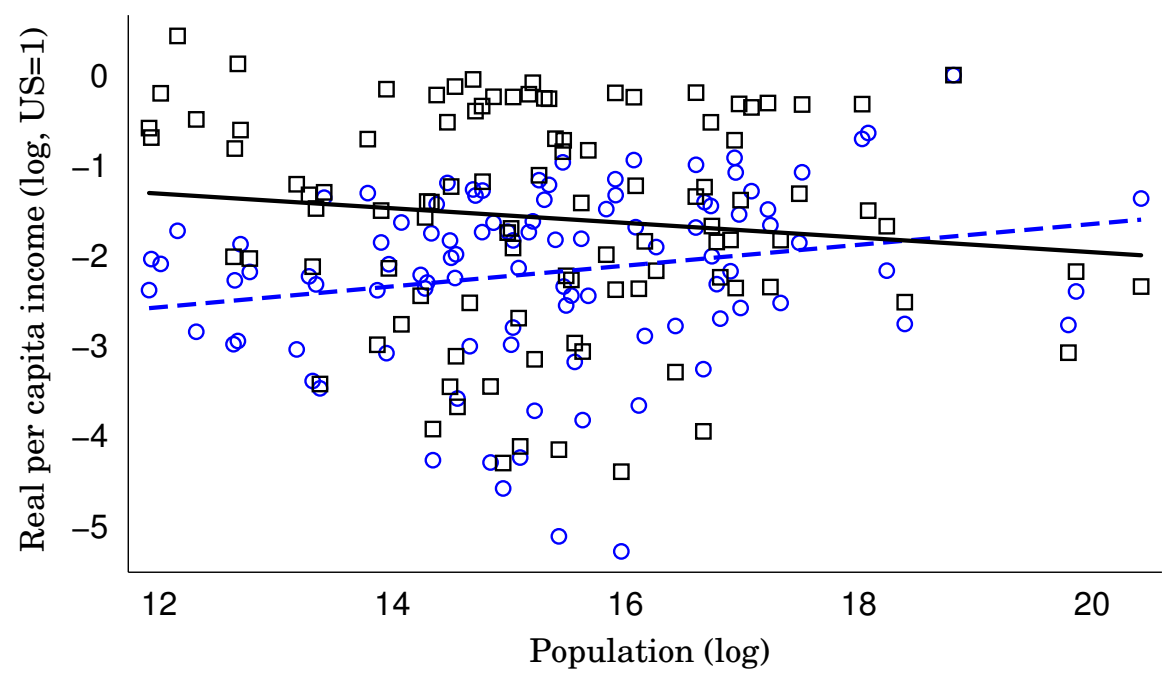


Figure 5: The gains from economic integration.

- Benchmark (adjusted scale effects) o Krugman-Melitz

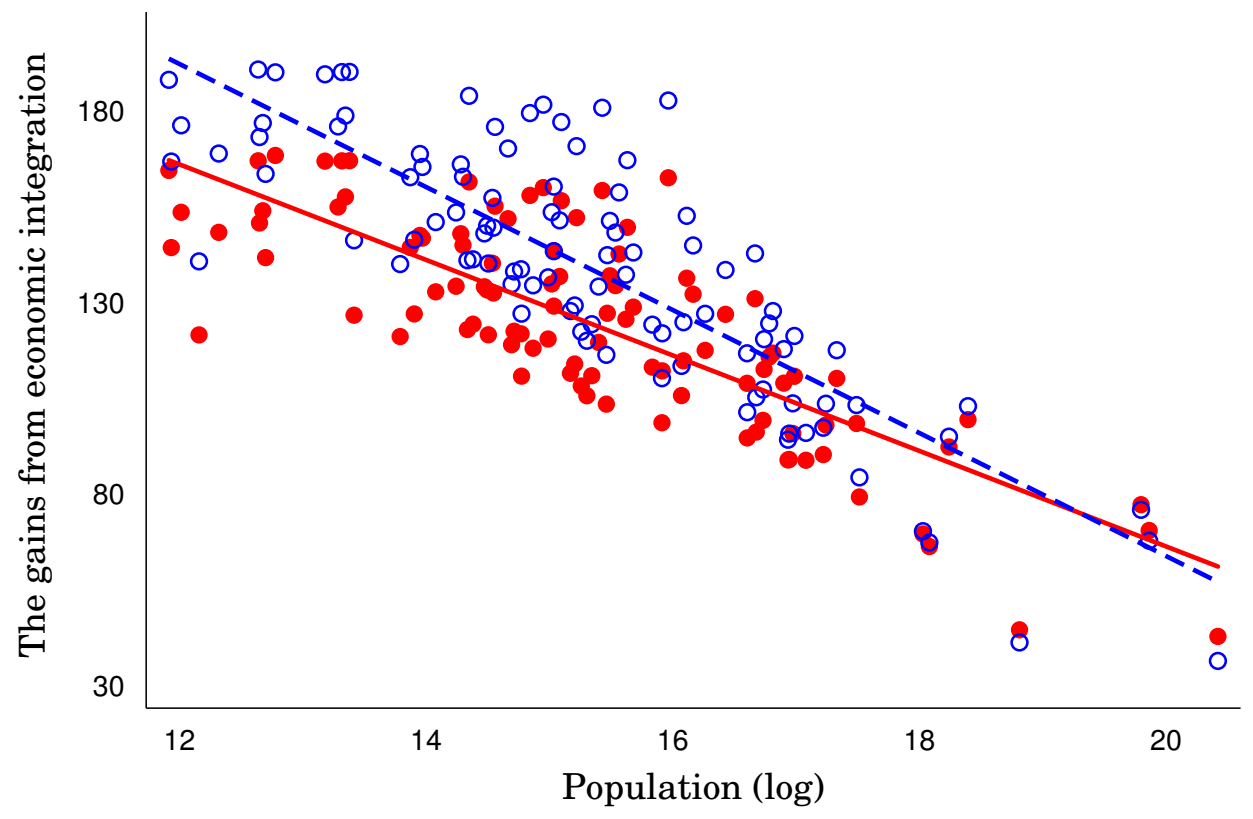

Figure 6: The gains from economic integration relative to the gains from political integration.

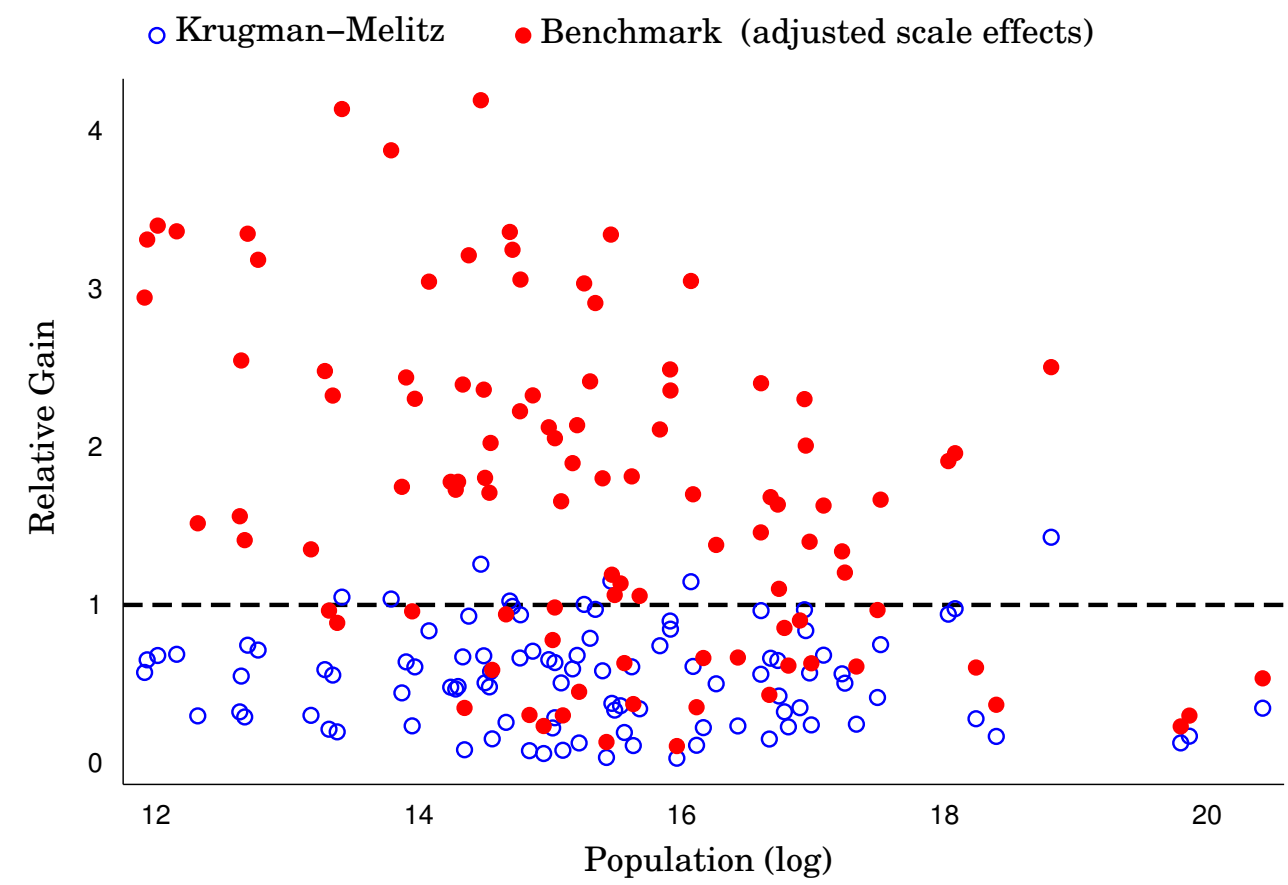


litical systems and the language) forces technologies and products to become more homogeneous. Economic integration, by contrast, permits the development and free trade of highly differentiated products across borders.

Formally speaking, consider a symmetric world with $N$ countries, each with a population $L$. The real per-capita income under economic integration would be $W_{E}=\gamma\left(N \times L^{\alpha}\right)^{\frac{1}{\theta}}$. Under political integration, we have one country with a population $N \times L$ and a real per capita income equal to $W_{P}=\gamma(N \times L)^{\frac{\alpha}{\theta_{2}}}$. Hence, the real per capita income of the economically integrated world relative to the politically integrated world would be

$$
\frac{W_{E}}{W_{P}}=N^{(1-\alpha) / \theta}
$$

Provided that $N>1$ and $\alpha<1$, it follows that $W_{E}>W_{P}$. We can quantify these effects by conducting two counterfactual analyses: (i) eliminating international trade costs, which corresponds to economic integration, and (ii) eliminating political borders, bundling all countries together, which corresponds to political integration. ${ }^{17}$ Figure 6 plots the gains from economic integration relative to those from political integration against population size. Compared to the baseline Krugman-Melitz model, the benchmark model predicts 70\% higher gains from economic integration (free trade across political borders) than political integration.

Altogether, the above analysis sheds light on the possible origins of the "congestion cost," which underlies theories of optimal country size (e.g., Alesina et al. (2000) or Alesina and Spolaore (2005)). Our analysis, however, is too stylized to deliver a general resolution. We identify one of the many advantages (or disadvantages) of political disintegration. For example, political disintegration will hamper trade through the so-called border effect, which is not accounted for in our analysis. Overall, a comprehensive assessment of political disintegration should account for a long list of relevant factors and the corresponding trade-offs, which is beyond the scope of this paper.

\footnotetext{
${ }^{17}$ The efficiency level in the politically integrated world is the population-weighted average of national efficiency levels.
} 


\section{Conclusion}

We estimated the scale elasticity across a wide range of tradable sectors. Using our estimated elasticities, we computed revised estimates for the gains from trade. To estimate the scale elasticity, we relaxed the strong parametric restrictions that are typically imposed on the import demand function. In that regard, our empirical analysis constitutes a basic step towards a less-parametric import demand estimation and paves the way for future advances on this front. At a broader level, this line of research could ultimately deliver less-parametric estimates of the gains from trade.

\section{References}

Adao, R., A. Costinot, and D. Donaldson (2015). Nonparametric counterfactual predictions in neoclassical models of international trade. Technical report, National Bureau of Economic Research.

Alesina, A. and E. Spolaore (2005). The size of nations. Mit Press.

Alesina, A., E. Spolaore, and R. Wacziarg (2000). Economic integration and political disintegration. American Economic Review 90(5), 1276-1296.

Alvarez, F. and R. E. Lucas (2007). General equilibrium analysis of the eatonkortum model of international trade. Journal of monetary Economics 54(6), $1726-1768$.

Anderson, J. E. (1979). A theoretical foundation for the gravity equation. The American Economic Review, 106-116.

Anderson, J. E. and E. Van Wincoop (2003). Gravity with gravitas: A solution to the border puzzle. The American Economic Review 93(1), 170-192.

Arkolakis, C., A. Costinot, and A. Rodriguez-Clare (2012). Clare, 2012, new trade models, same old gains. American Economic Review 102(1), 94.

Arrow, K. J. (1950). A difficulty in the concept of social welfare. The Journal of Political Economy, 328-346.

Bartik, T. J. (1991). Who Benefits from State and Local Economic Development Policies? W.E. Upjohn Institute for Employment Research. 
Berry, S., J. Levinsohn, and A. Pakes (1995). Automobile prices in market equilibrium. Econometrica: Journal of the Econometric Society, 841-890.

Berry, S. T. (1994). Estimating discrete-choice models of product differentiation. The RAND Journal of Economics, 242-262.

Bhagwati, J. N. (1982). Shifting comparative advantage, protectionist demands, and policy response. In Import competition and response, pp. 151-196. University of Chicago Press.

Broda, C. and D. E. Weinstein (2006). Globalization and the gains from variety. The Quarterly Journal of Economics 121(2), 541-585.

Caliendo, L. and F. Parro (2014). Estimates of the trade and welfare effects of nafta. The Review of Economic Studies, rdu035.

Chaney, T. (2008). Distorted gravity: the intensive and extensive margins of international trade. The American Economic Review 98(4), 1707-1721.

Comtrade, U. (2010). United nations commodity trade statistics database. URL: http://comtrade. un. org.

Costinot, A. and A. Rodríguez-Clare (2014). Trade theory with numbers: Quantifying the consequences of globalization. Handbook of International Economics 4, 197.

Eaton, J. and S. Kortum (2001). Technology, trade, and growth: A unified framework. European economic review 45(4), 742-755.

Eaton, J. and S. Kortum (2002). Technology, geography, and trade. Econometrica 70(5), 1741-1779.

Eaton, J., S. Kortum, and F. Kramarz (2011). An anatomy of international trade: Evidence from french firms. Econometrica 79(5), 1453-1498.

Feenstra, R. (1982). Appendix. product creation and trade patterns: a theoretical note on the biological model of trade in similar products. Import competition and response. Chicago: University of Chicago.

Fernandes, A. M., P. J. Klenow, S. Meleshchuk, and M. D. Pierola (2015). The intensive margin in trade: Moving beyond pareto. 
Hausman, J. A. (1996). Valuation of New Goods under Perfect and Imperfect Competition. In The Economics of New Goods, NBER Chapters, pp. 207-248. National Bureau of Economic Research, Inc.

Head, K. and J. Ries (2001). Increasing returns versus national product differentiation as an explanation for the pattern of us-canada trade. American Economic Review, 858-876.

Hummels, D. and P. J. Klenow (2005). The variety and quality of a nation's exports. The American Economic Review 95(3).

Jones, C. I. (1999). Growth: with or without scale effects? The American Economic Review 89(2), 139-144.

Khandelwal, A. (2010). The long and short (of) quality ladders. The Review of Economic Studies 77(4), 1450-1476.

Kortum, S. S. (1997). Research, patenting, and technological change. Econometrica: Journal of the Econometric Society, 1389-1419.

Krugman, P. (1980). Scale economies, product differentiation, and the pattern of trade. The American Economic Review 70(5), 950-959.

Kucheryavyy, K., G. Lyn, and A. Rodríguez-Clare (2015). External economies and international trade: A quantitative framework.

Manski, C. F., D. McFadden, et al. (1981). Structural analysis of discrete data with econometric applications. Mit Press Cambridge, MA.

Mayer, T. and S. Zignago (2011). Notes on cepiis distances measures: The geodist database.

Melitz, M. (2003). The impact of trade on aggregate industry productivity and intra-industry reallocations. Econometrica 71(6), 1695-1725.

Ramondo, N. and A. Rodríguez-Clare (2010). Growth, size, and openness: a quantitative approach. The American Economic Review 100(2), 62.

Ramondo, N., A. Rodríguez-Clare, and M. Saborío-Rodríguez (2016, October). Trade, domestic frictions, and scale effects. American Economic Review 106(10), 3159-84. 
Redding, S. J. and D. E. Weinstein (2016). A unified approach to estimating demand and welfare. Working Paper.

Rose, A. K. (2006). Size really doesn't matter: In search of a national scale effect. Journal of the Japanese and international Economies 20(4), 482-507.

Silva, J. S. and S. Tenreyro (2006). The log of gravity. The Review of Economics and statistics 88(4), 641-658.

Simonovska, I. and M. E. Waugh (2014). The elasticity of trade: Estimates and evidence. Journal of international Economics 92(1), 34-50.

Waugh, M. (2010). International trade and income differences. The American Economic Review 100(5), 2093-2124.

World-Bank (2012). World Development Indicators 2012. World Bank-free PDF.

\section{A Proof of Proposition 1}

Part 1: Trade Shares in the Idea-Based Model. The demand equation in the variety-based model is standard, below we show how to derive the structural import demand function in the idea-based model. As a starting point, notice that consumers face a discrete choice problem that has the following structure:

$$
\min _{\omega} \frac{p_{\omega i, h}}{\varphi_{\omega}(v)} \sim \max _{\omega}-\ln \frac{p_{\omega i, h}}{\varphi_{\omega}(v)}=-\ln p_{\omega i, h}+\ln \varphi_{\omega}(v) .
$$

Define $G(c)$ as follows

$$
G_{h}(\mathbf{c})=\sum_{k=1}^{N}\left(\sum_{\omega \in \Omega_{k i, h}} T_{\omega, h} \exp \left(-\vartheta_{h} \ln p_{\omega i, h}\right)\right)^{\frac{\theta_{h}}{\vartheta_{h}}}=\sum_{k=1}^{N}\left(\sum_{\omega \in \Omega_{k i, h}} T_{\omega, h} p_{\omega i, h}^{-\vartheta_{h}}\right)^{\frac{\theta_{h}}{\vartheta_{h}}}=\sum_{k=1}^{N}\left(\sum_{\omega \in \Omega_{k i, h}} c_{\omega i, h}^{\vartheta_{h}}\right)^{\frac{\theta_{h}}{\vartheta_{h}}}
$$

where $c_{\omega i, h} \equiv T_{\omega, h}^{1 / \vartheta_{h}} p_{\omega i, h}^{-1}$. Note that $G_{h}($.$) is a continuous and differentiable func-$ tion of vector $\mathbf{c}$ (where ) and has the following properties:

i. $G_{h}() \geq$.0 ;

ii. $G_{h}($.$) is a homogeneous function of \operatorname{rank} \theta_{h}: G_{h}(\rho \mathbf{c})=\rho^{\theta_{h}} G_{h}(\mathbf{c})$;

iii. $\lim _{\mathcal{c}_{\omega i, h} \rightarrow \infty} G_{h}(\mathbf{c})=\infty, \forall \omega$; 
Table 7: The Gains From Trade.

\begin{tabular}{|c|c|c|c|c|c|}
\hline & \multicolumn{3}{|c|}{ Gains from Trade } & \multicolumn{2}{|c|}{ Specialization } \\
\hline & Benchmark & EK-Armington & Krugman & Degree & Scale-Intesity \\
\hline Country & $(1)$ & $(2)$ & (3) & $(4)$ & (5) \\
\hline AUS & $6.8 \%$ & $9.2 \%$ & $4.0 \%$ & 4.58 & -19.41 \\
\hline AUT & $29.5 \%$ & $29.6 \%$ & $29.5 \%$ & 1.97 & 1.27 \\
\hline BEL & $31.1 \%$ & $31.4 \%$ & $30.9 \%$ & 9.31 & 5.10 \\
\hline BRA & $3.9 \%$ & $4.4 \%$ & $3.8 \%$ & 0.49 & -4.26 \\
\hline CAN & $17.7 \%$ & $19.2 \%$ & $16.5 \%$ & 3.16 & -12.91 \\
\hline $\mathrm{CHN}$ & $9.0 \%$ & $7.9 \%$ & $9.9 \%$ & 2.04 & 13.60 \\
\hline $\mathrm{CZE}$ & $24.7 \%$ & $23.7 \%$ & $26.9 \%$ & 1.84 & 13.13 \\
\hline DEU & $17.7 \%$ & $16.3 \%$ & $20.2 \%$ & 4.20 & 19.71 \\
\hline DNK & $23.3 \%$ & $23.8 \%$ & $20.9 \%$ & 11.56 & 4.67 \\
\hline ESP & $10.0 \%$ & $10.8 \%$ & $10.0 \%$ & 2.90 & -5.19 \\
\hline FIN & $13.7 \%$ & $12.5 \%$ & $14.1 \%$ & 4.64 & 16.23 \\
\hline FRA & $12.0 \%$ & $11.7 \%$ & $12.7 \%$ & 2.52 & 4.78 \\
\hline GBR & $13.1 \%$ & $13.9 \%$ & $12.4 \%$ & 1.01 & -7.80 \\
\hline GRC & $10.1 \%$ & $14.6 \%$ & $4.6 \%$ & 14.03 & -32.54 \\
\hline HUN & $42.1 \%$ & $41.6 \%$ & $43.7 \%$ & 3.43 & 11.81 \\
\hline IDN & $7.4 \%$ & $8.4 \%$ & $6.0 \%$ & 1.63 & -8.64 \\
\hline IND & $5.4 \%$ & $5.9 \%$ & $5.3 \%$ & 1.69 & -3.66 \\
\hline IRL & $18.3 \%$ & $17.5 \%$ & $16.2 \%$ & 8.83 & 17.50 \\
\hline ITA & $9.1 \%$ & $9.0 \%$ & $8.9 \%$ & 3.34 & 3.37 \\
\hline JPN & $4.7 \%$ & $3.6 \%$ & $7.2 \%$ & 5.20 & 14.74 \\
\hline KOR & $11.4 \%$ & $9.5 \%$ & $15.4 \%$ & 16.97 & 35.56 \\
\hline MEX & $16.0 \%$ & $16.4 \%$ & $17.0 \%$ & 2.24 & -2.80 \\
\hline NLD & $22.4 \%$ & $21.9 \%$ & $21.6 \%$ & 2.54 & 7.40 \\
\hline POL & $19.9 \%$ & $20.3 \%$ & $20.5 \%$ & 1.12 & -2.61 \\
\hline PRT & $18.8 \%$ & $20.3 \%$ & $17.3 \%$ & 4.04 & -12.99 \\
\hline $\mathrm{ROM}$ & $17.4 \%$ & $19.6 \%$ & $15.3 \%$ & 2.62 & -21.61 \\
\hline RUS & $10.1 \%$ & $15.1 \%$ & $1.3 \%$ & 9.80 & -41.32 \\
\hline SVK & $36.7 \%$ & $36.4 \%$ & $38.6 \%$ & 4.87 & 9.03 \\
\hline SVN & $34.0 \%$ & $34.2 \%$ & $33.8 \%$ & 14.35 & 11.69 \\
\hline SWE & $16.6 \%$ & $16.0 \%$ & $17.9 \%$ & 2.43 & 9.61 \\
\hline TUR & $12.1 \%$ & $12.4 \%$ & $12.6 \%$ & 2.28 & -0.80 \\
\hline TWN & $26.6 \%$ & $24.5 \%$ & $28.4 \%$ & 14.40 & 39.09 \\
\hline USA & $5.2 \%$ & $6.1 \%$ & $4.6 \%$ & 1.00 & -7.83 \\
\hline RoW & $14.7 \%$ & $17.2 \%$ & $10.4 \%$ & 6.42 & -19.90 \\
\hline
\end{tabular}


iv. the $k^{\prime}$ th partial derivative of $G_{h}($.$) with respect to a generic combination$ of $k$ variables $c_{\omega i, h}$, is non-negative if $k$ is odd and non-positive if $k$ is even.

Manski et al. (1981) show that if $G_{h}($.$) satisfies the above conditions, and \phi_{\omega}(v)$ 's are drawn from the following distribution:

$$
F_{h}(\boldsymbol{\varphi})=\exp \left(-G_{h}\left(e^{-\ln \varphi}\right)\right)=\exp \left(-\sum_{k=1}^{N}\left(\sum_{\omega \in \Omega_{k i, h}} T_{\omega, h} \varphi_{\omega}^{-\vartheta_{h}}\right)^{\frac{\theta_{h}}{\vartheta_{h}}}\right) ;
$$

the probability of choosing variety $\omega$ from country of origin $j$ is

$$
\begin{aligned}
\lambda_{\omega i, h} & =\frac{\left(\frac{c_{\omega i, h}}{\theta_{h}}\right) \frac{\partial G_{h}}{\partial c_{\omega i, h}}}{G_{h}(\mathbf{c})}=\frac{c_{\omega i, h} c_{\omega i, h}^{\vartheta_{h}-1}\left(\sum_{\omega^{\prime} \in \Omega_{j i, h}} c_{\omega^{\prime} i, h}^{\vartheta_{h}}\right)^{\frac{\theta_{h}}{\vartheta_{h}}-1}}{\sum_{k=1}^{N}\left(\sum_{\omega^{\prime} \in \Omega_{k i, h}} c_{\omega^{\prime} i, h}^{\vartheta_{h}}\right)^{\frac{\theta_{h}}{\vartheta_{h}}}} \\
= & \frac{c_{\omega i, h}^{\vartheta_{h}}}{\sum_{\omega^{\prime} \in \Omega_{j i, h}} c_{\omega^{\prime} i, h}^{\vartheta_{h}}} \cdot \frac{\left(\sum_{\omega^{\prime} \in \Omega_{j i, h}} c_{\omega_{h}^{\prime} i, h}^{\vartheta_{h}}\right)^{\frac{\theta_{h}}{\vartheta_{h}}}}{\sum_{k=1}^{N}\left(\sum_{\omega^{\prime} \in \Omega_{k i, h}} c_{\omega^{\prime} i, h}^{\vartheta_{h}}\right)^{\frac{\theta_{h}}{\vartheta_{h}}}} .
\end{aligned}
$$

Defining $\phi_{\omega, h}=T_{\omega, h}^{\alpha_{h} / \vartheta_{h}}$ and noting that $\alpha_{h} \equiv \theta_{h} / \vartheta_{h} ;$ we can replace $c_{\omega i, h}=p_{\omega i, h} / \phi_{\omega, i}$ in the above equation to arrive a

$$
\lambda_{\omega i, h}=\left(\frac{p_{\omega i, h} / \phi_{\omega, h}}{P_{j i, h}}\right)^{-\frac{\theta_{h}}{\alpha_{h}}}\left(\frac{P_{j i, h}}{P_{i, h}}\right)^{-\theta_{h}}
$$

where $P_{j i, h} \equiv\left[\sum_{\omega^{\prime} \in \Omega_{j i, h}}\left(p_{\omega^{\prime} i, h} / \phi_{\omega^{\prime}, h}\right)^{-\theta_{h} / \alpha_{h}}\right]^{-\alpha_{h} / \theta_{h}}$ and $P_{i, h} \equiv\left[\sum P_{j i, h}^{-\theta_{h}}\right]^{-\frac{1}{\theta_{h}}}$.

Part 2: Deriving the Log-Linear Import Demand Function. At this point, we have established that both idea-based and variety-based models imply the following import demand function for market $i$ :

$$
x_{\omega i, h}=\left(\frac{p_{\omega i, h} / \phi_{\omega i, h}}{P_{j i, h}}\right)^{-\frac{\theta_{h}}{\alpha_{h}}}\left(\frac{P_{j i, h}}{P_{i, h}}\right)^{-\theta_{h}} \times \beta_{h} Y_{i} .
$$


We can rearrange the above equation as

$$
\begin{aligned}
x_{\omega i, h} & =\left(\frac{p_{\omega i, h}}{\phi_{\omega i, h}}\right)^{-\theta_{h}}\left(\frac{p_{\omega i, h}}{\phi_{\omega i, h}}\right)^{\theta_{h}-\frac{\theta_{h}}{\alpha_{h}}} \cdot P_{j i, h}^{\frac{\theta_{h}}{\alpha_{h}}-\theta_{h}} \cdot P_{i, h}^{\theta_{h}} \times \beta_{h} Y_{i} \\
& =\left(\frac{p_{\omega i, h}}{\phi_{\omega i, h}}\right)^{-\theta_{h}}\left(\frac{p_{\omega i, h} / \phi_{\omega i, h}}{P_{j i, h}}\right)^{-\frac{\theta_{h}}{\alpha_{h}}\left(1-\alpha_{h}\right)} \cdot P_{i, h}^{\theta_{2}} \times \beta_{h} Y_{i} .
\end{aligned}
$$

Noting that $\lambda_{\omega \mid j i, h}=\left(\frac{p_{\omega i, h} / \phi_{\omega i, h}}{P_{j i, h}}\right)^{-\frac{\theta_{h}}{\alpha_{h}}}$ and taking logs, the above equation will become:

$$
\ln x_{\omega i, h}=-\theta_{h} \ln p_{\omega i, h}+\left(1-\alpha_{h}\right) \ln \lambda_{\omega \mid j i, h}+\underbrace{\theta_{h} \ln P_{i, h}+\ln \beta_{h} Y_{i}}_{\Psi_{i, h}}+\phi_{\omega i, h} .
$$

